\title{
Design and performance enhancement of a dense wavelength division multiplexing MIMO-FSO systems using DPPM and OOK modulation
}

\author{
Ebrahim E. Elsayed \\ Electronics and Communications Engineering Department, Faculty of Engineering, Mansoura University, Mansoura 35516, El-Dakahilia \\ Governorate, Egypt. \\ Author's email address: engebrahem16@gmail.com
}

\begin{abstract}
In this paper, we design and analyze the dense wavelength division multiplexing (DWDM) in the multiple-input multiple-output (MIMO) free-space optical (FSO) communications system using the digital-pulse position modulation (DPPM) and on-off keying (OOK). We show the effects noises, interchannel crosstalk, and atmospheric turbulence for the proposed system in the weak and strong turbulence with the modulation techniques. DWDM channels suffer from the inter-channel crosstalk while the communication performance in an obviously limited by the MIMO-FSO caused by atmospheric scintillation. All Impairments, in addition to noises of the optical amplification which is emerged the amplified spontaneous emission and are likely to be problematic, particularly in the upstream direction, which are investigated, the results obtained a high enough crosstalk ratio can achieve access to high-capacity in a system network safe and human. DPPM is a more power efficient modulation and lower power penalty $0.2 \sim 0.3 \mathrm{~dB}$ from the OOK modulation.
\end{abstract}

Keywords: atmospheric turbulence channel; MIMO-FSO systems; on-off keying; dense wavelength division multiplexing (DWDM); amplified spontaneous emission noise.

\section{INTRODUCTION}

$\mathrm{A}$ LTHOUGH linking communication in free space in the optical spectrum instead of the radio one allows ignoring license requirements, improving security, and transmitting data with broad spectrum, optical technologies carrier can have access to a good network where they could potentially provide huge bandwidth but it suffers from fluctuations in temperature and pressure that occur in the atmosphere regularly $[1,2]$. Free space optics (FSO) with dense wavelength division multiplexing (DWDM) can increase the number of channels and thus helps to enhance the technical capacity and use for long distance data transmission. There are three types of WDM that are commonly used: Coarse WDM (CWDM), Dense WDM (DWDM) and Broadband WDM. DWDM is a technology which multiplexes multiple optical carrier signals on a single medium by using different signals with huge channel capacity and the wavelength range from $1539 \mathrm{~nm}$ to $1565 \mathrm{~nm}$ is the most commonly located in CBand and contribute in reducing bandwidth usage and can support capacity to reach Terabits per second and are easily to increase a data rate into the FSO [3]. Passive optical networks (PON) (i.e. the last mile connection between individual homes and companies) and the general network and gradually replace the copper on the basis of network access technologies [4, 5]. WDM is the next generation of dissemination of FSO based access network which offer higher bandwidth [6,7]. With (WDM-PON), is set fixed wavelengths for each optical network unit (ONU), and thus more fully exploit the high transfer bandwidth available in the optical domain $[8,9]$. (WDM-PON) systems offer greater security, increase bandwidth and less loss compared to time division ultiple access (TDM/TDMA) [3, 10-12]. Optical amplifier (OAs) is important for the long distances in the free space optics. The transporters for deploy (WDM) are remain the same as whether by integrated the dioital nulse nosition modulation (DPPM) or conventional on-off keying (OOK). Interchannel crosstalk is proclaimed in [5, 12]. OnOff Keying (OOK) and Pulse Position Modulation (DPPM) are the most modulation format of atmospheric turbulence using intensity of photon. The digital pulse position modulation (PPM) is one of the modulation technique has high power efficiency compared to On-Off Keying (OOK) [13-15]. It has been successfully applied in the optical fiber, satellite, terrestrial for FSO and deep space optical communication. It has been achieved of greater channel bandwidth requirements. Wavelength division multiplexed (WDM-PONs) are a natural development of the (PON) concept and various architectures are possible. The turbulence accentuation of interchannel occurs when the signal paths and crosstalk are turbulent independently (from being physically quite distinct) so that mutual strength may close temporarily or even considerably exceeds the signal strength despite the average long - time signal to crosstalk ratio [10]. Multiple laser sources from different wavelengths in the system raises the problem optical crosstalk. In (WDM-PON), crosstalk interchannel and naturally, unless the wavelength narrow spacing in particular it will features a purely amount of contribution to the intensities and no interferometric contribution. Due to problem the crosstalk present design laser transceiver with alignment based on computer and steeper motor to solve problem transmitter beam divergence and losses of beam spreading FSO can be reduced significantly by creating multiple inputs and multiple outputs (MIMO) FSO system with multiple transmitter and receiver antennas [16, 17]. This wireless technology has improved significantly in the capacity range and increases the reliability of transmission. For MIMO WDM/FSO we assume repetition coding across lasers at the transmitter $[17,18]$ and equal gain combining (EGC) and maximal ratio combining (MRC) at the receiver. To this end, the topology of WDM-FSO PON proven to be effective to achieve strong link and designing 


\section{SYSTEM DESIGN AND ANALYSIS}

Consider a typical (WDM- PON/FSO) system, where connects a multiwavelength optical line terminator (OLT) to optical network unit $[8,9,10]$. The distance can reach of up to $20 \mathrm{~km}$ using PON. The network component as shown in [10] include An arrayed waveguide grating (AWG) for DWDM, laser driver (LD), laser generates for optical signal and modulation format (PPM mod) and receiver with multiple a photodetector, single mode fiber, Optical amplifier and the integrate and compare circuitry (ICC) for system decision. WDM/FSO-PON is based on multiplexing of user on a shared fiber infrastructure using a specific wavelength for each terminal. This method creates a virtual connection from point to point, which allow full duplex transmission with optical bit rates independently of the traffic caused by other users. For the long distance from OLT to optical network unit, employed multihop WDM/relaying with erbium doped fiber amplifier (EDFA). Interchannel crosstalk occurs because of the nature of the perfection of demux (in OLT to move upstream or RN for the transfer of downstream). The effect of turbulence-accentuated interchannel crosstalk in WDM-PON integrated with FSO networks was investigated in [10]. The Optical wavelengths are selected in band C (about $1550 \mathrm{~nm}$ ) with $100 \mathrm{GHz}$ channel spacing, for $1550 \mathrm{~nm}$ light suffered less atmospheric attenuation. In the upstream each optical network unit independent transmit to OLT with laser of fixed wavelength $\lambda_{1}, \lambda_{2}, \lambda_{\mathrm{n}}$, where $\mathrm{N}$ is the number of ONUs in direction receiver collecting lenses (RCLs) may include optical bandpass filter(OBPF). In high-capacity environments, the WDM extension DWDM operates with channel spacing as small as 0.8 or $0.4 \mathrm{~nm}$, at $1-40 \mathrm{~Gb} / \mathrm{ps}$. Each remote node RCL couples arranged wavelength through a short length of fiber (using fiber collimator as in [19]. In the downstream OLT transmit signals with $\mathrm{N}$ of wavelengths with DWDM of range located in C-Band to group of the optical network unit ONUs and signals from the transmitters $K$, each with unique wavelength $\left(\lambda_{1}, \lambda_{2}, \lambda_{k}\right)$ is combined by WDM mux (Lmux) and then transported via multihop FSO cahnnels to RN of optical network unit (ONU), OLT transmit powers with maximum $\leq 10 \mathrm{dBm}$. WDM/FSO-PON with DPPM system does not tracking adaptive threshold unlike some OOK systems. [20]. In Section 6, present analysis of WDMPON /FSO WITH DPPM.

\section{ATMOSPHERIC TURBULENCE CHANNEL MODELING}

Atmospheric turbulence is occurs due to by temperature difference between the earth's surface and atmosphere. Atmospheric turbulence can be characterized by three parameters: the inner scale $l_{o}$, the outer scale $l_{o}$, and the index of the refraction structure parameter $\mathrm{C}_{\mathrm{n}}^{2}$, sometimes called the turbulence strength [21]. This effects of turbulence, weak, moderate, and strong are characterized using the "GAMMA-GAMMA" (GG) distribution probability density function (PDF) which given as [22-24].

$$
\begin{array}{r}
\mathrm{P}_{\mathrm{GG}}\left(\mathrm{h}_{\mathrm{X}}\right)=\frac{2(\alpha \beta)^{(\alpha+\beta)} / 2}{\Gamma(\alpha) \Gamma(\beta)} \mathrm{h}_{\mathrm{X}}{ }^{(\alpha+\beta) / 2-1 \mathrm{~K}_{\alpha-\beta}\left(2 \sqrt{\left.\alpha \beta h_{X}\right)}\right.} \\
; h_{X}>0
\end{array}
$$

where $h_{X}$ is the attenuation due to atmospheric turbulence for the signal $\left(h_{\text {sig }}\right)$ or interfere $r\left(h_{\text {int }}\right), \alpha$ is the effective number of largescale eddies of the scattering process, $\beta$ is the effective number of small-scale eddies of the scattering process, $K_{n}(\cdot)$ is the gamma function. The signal and interferer travel over physically distinct paths in the upstream.

$$
\begin{aligned}
& \alpha=\left\{\exp \left[\frac{0.49 \sigma_{\mathrm{R}}^{2}}{\left(1+0.65 d^{2}+1.11 \sigma_{\mathrm{R}}^{12 / 5}\right)^{7 / 6}}\right]-1\right\}^{-1} \\
& \beta=\left\{\exp \left[\frac{0.51 \sigma_{\mathrm{R}}^{2}\left(1+0.69 \sigma_{R}^{12 / 5}\right)^{-5 / 6}}{1+0.9 d^{2}+0.62 d^{2} \sigma_{\mathrm{R}}^{12 / 5}}\right]-1\right\}^{-1}
\end{aligned}
$$

as written in [22-24]. Where $\mathrm{d}=\sqrt{\mathrm{KD}_{\mathrm{RX}}^{2} / 4 \mathrm{l}_{\mathrm{fso}}}$ is the normalized $\mathrm{RCL}$ radius, $\sigma_{\mathrm{R}}^{2}=1.23 \mathrm{C}_{\mathrm{n}}^{2} \mathrm{~K}^{7 / 6} 1_{\mathrm{fs}}^{11 / 6}[18], \mathrm{C}_{\mathrm{n}}^{2}$ is the refractive index structure constant (ranging from $\approx 10^{-17} \mathrm{~m}^{-2 / 3}$ to $\sim 10^{-13} \mathrm{~m}^{-2 / 3}$ ), $\mathrm{l}_{\text {fso }}$ is the FSO link length, $\mathrm{k}=2 \pi / \lambda$ is the wave number [22-26].

\section{GENERAL BER ANALYSIS}

The BERs Conditional under the assumption of independent signal and crosstalk channels for upstream and downstream are, respectively, written as [10].

$\overline{\mathrm{BER}}=\iint_{0}^{\infty} \operatorname{BER}\left(h_{s i g}, h_{i n t}\right) P_{G G, s i g}\left(\mathrm{~h}_{\text {sig }}\right) P_{G G, i n t}\left(\mathrm{~h}_{\text {int }}\right) \mathrm{d} h_{s i g} d h_{i n t}$

where $\mathrm{P}_{\mathrm{GG} \text {,sig }}\left(\mathrm{h}_{\mathrm{sig}}\right)$ and $\mathrm{P}_{\mathrm{GG}, \text { sig }}\left(\mathrm{h}_{\mathrm{int}}\right)$ are respectively, the signal and interferer GG pdfs ( each with different $\alpha, \beta$ and $\sigma_{\mathrm{R}}^{2}$ ) as writen in [10].

$$
\begin{array}{r}
\operatorname{BER}\left(h_{\text {sig }}, h_{\text {int }}\right)=\frac{1}{4} \operatorname{erfc}\left(\frac{\mathrm{Q}\left(h_{\text {sig }}, h_{\text {int }}\right)}{\sqrt{2}}\right) \\
Q\left(h_{\text {sig }}, h_{\text {int }}\right)=\frac{\mathrm{i}_{1,0}\left(h_{\text {sig }}, h_{\text {int }}\right)-\mathrm{i}_{0,1}\left(h_{\text {sig }}, h_{\text {int }}\right)}{\sigma_{1,0}\left(h_{\text {sig }}, h_{\text {int }}\right)+\sigma_{0,1}\left(h_{\text {sig }}, h_{\text {int }},\right)}
\end{array}
$$

where $d_{\text {sig }}=0$ or 1 or $d_{\text {int }}=0$ or 1 current at decision cuircuit

\subsection{THE UPSTREAM ANALYSIS}

The Average received optical power at the OLT photodiode for the desired signal and an interferer is given, respectively, as equation written in $[10,13]$.

$$
\begin{aligned}
& \mathrm{P}_{\mathrm{R}, \text { sig }}\left(\mathrm{h}_{\text {sig }}\right)=\mathrm{GP}_{\mathrm{UT}, \text { sig }} \mathrm{h}_{\text {sig }} \mathrm{L}_{\mathrm{fso.sig}} \mathrm{L}_{\mathrm{bs} \text {,sig }} \mathrm{L}_{\mathrm{c}, \mathrm{si}} \mathrm{L}_{\text {mux }} \mathrm{L}_{\text {fiber }} \mathrm{L}_{\text {demux }} \\
& \mathrm{P}_{\mathrm{R}, \text { int }}\left(\mathrm{h}_{\text {int }}\right)=\mathrm{GP}_{\mathrm{UT}, \mathrm{nt}} \mathrm{h}_{\text {int }} \mathrm{L}_{\text {fso.int }} \mathrm{L}_{\mathrm{bs}, \text { int }} \mathrm{L}_{\mathrm{c}, \text { int }} \mathrm{L}_{\text {mux }} \mathrm{L}_{\text {fiber }} \mathrm{L}_{\text {demux }} \mathrm{L}_{\text {demux }, \mathrm{XT}}
\end{aligned}
$$

where $G$ is gain optical amplifier, $L_{\text {demux, } X T}$ is the crosstalk i.e. additional loss (above $L_{\text {demux }}$ ) the interferer has when coupled onto the signal photodiode by the demux. + . The fiber loss $\left(\mathrm{L}_{\mathrm{fiber}}=\right.$ $\left.10^{-\alpha(f i b e r / f i b e r) / 10}\right)$ is the loss due to fiber attenuation and $-\propto_{\text {(fiber) }}$ is the fiber attenuation factor in $\mathrm{dB} / \mathrm{Km}$. The loss due to beam spreading $L_{b s}$ in the FSO link for signal and interferer can be calculated from $[23,24]$.

$$
\mathrm{L}_{\mathrm{bs}}=\left[\frac{D_{R X}}{\theta_{l f s o}}\right]^{2}
$$

$\mathrm{L}_{\mathrm{C}}$ - the coupling Loss for the signal and interferer can be calculated from [25], $\mathrm{N}_{\mathrm{O}}=0.5(\mathrm{NFG}-1) h_{n} L_{f} L_{\text {demux }}$ where $\mathrm{G}$ and $\mathrm{NF}$ are the OA gain and noise figure, respectively, $h$ is Planck's constant. 


\subsection{THE DOWNSTREAM TRANSMISSION.}

The average received optical power at the ONU photodiodes for desired signal and interferer are given, respectively, as written in [10]:

$$
\mathrm{P}_{\mathrm{dR}, \text { sig }}\left(\mathrm{h}_{\text {turb }}\right)=\mathrm{GP}_{\mathrm{dT} \text {,sig }} \mathrm{h}_{\text {turb }} \mathrm{L}_{\text {mux }} \mathrm{L}_{\text {fiber }} \mathrm{L}_{\text {demux }} \mathrm{L}_{\mathrm{fso}} \mathrm{L}_{\mathrm{bs}}
$$

$\mathrm{P}_{\mathrm{dR} \text {,int }}\left(\mathrm{h}_{\text {turb }}\right)=\mathrm{GP}_{\mathrm{dT} \text {,int }} \mathrm{h}_{\text {turb }} \mathrm{L}_{\text {mux }} \mathrm{L}_{\text {fiber }} \mathrm{L}_{\text {demux,XT }} \mathrm{L}_{\mathrm{fso}}$

where $P_{d R, s i g}$ and $\mathrm{P}_{\mathrm{dR} \text {,int }}$ are the OLT transmitter power can used for the electric domain noises.

\subsection{ERROR FLOOR WITH USING OOK}

There is no single equation for the Required Average Power at a fixed BER By maintaining the BER at a fixed value and restructure the code for finding the BER to be able to calculate the Average Power that can give the fixed BER. This can be done using the root finding technique. Basically to find an average power value that will result in a BER value above the fixed BER value and another average power value that will result in a BER value below the fixed BER value. Then use the average powers that gave the higher and lower BER values as the upper and lower limit of the root finding search and then keep dissecting the space in between those two limits until get the approximate average power that can give the fixed BER. The analysis of BER versus average received power results, for FSO communication system under various atmospheric turbulence conditions, with the main focus on the turbulence accentuated of inter-channel crosstalk the thermal noise current is assumed to be 7 $\times 10^{-7}$, with back-to-back sensitivity of $-20 \mathrm{dBm}$ at BER of $10^{-12}$ The weak turbulence ( WT) and strong turbulence (ST) conditions for FSO link length $l=1000 \mathrm{~m}$ for $\mathrm{C}_{\mathrm{n}}^{2}=8.4 \times 10^{-15} \mathrm{~m}^{-2 / 3}$ and $\mathrm{C}_{\mathrm{n}}^{2}=1 \times 10^{-13} \mathrm{~m}^{-2 / 3}$. Results are obtained of analysis interchannel crosstalk with digital pulse position modulation (DPPM) for 1) no interferer, no turbulence(Si) 2) signal with turbulence, no interferer ( Turbu Si ); 3) signal with turbulence, interferer with no turbulence (Turbu Si,XT ); 4) signal with interferer, no turbulence ( $\mathrm{Si}, \mathrm{XT}$ ); and 5) signal with no turbulence, interferer with turbulence ( $\mathrm{Si}$, Turbu XT ). While the analysis of interchannel crosstalk using error floor appeard the first three cases only. The error floor is on the long time average BER i.e. same Rytov variance and thus scintillation pdf but averaging over the different outcomes that the scintillation could take from that pdf in the situation where signal is turbulent but crosstalk is not this means there is a fixed (data averaged) crosstalk power at the receiver. Due to scintillation the signal (averaged over data in the short term) will sometimes be above this crosstalk power and sometimes below it, and for a given average (long term i.e. over different scintillation states arising from same scintillation pdf) received signal power the fraction of the time that the signal is lower than the crosstalk is straightforwardly obtained from integrating the scintillation pdf with an appropriate $\mathrm{h}$ for a limit. Let us call the fraction $(<1)$ resulting from this integration F. Similarly in the situation where crosstalk is turbulent but signal is not this means there is a fixed (data averaged) signal power at the receiver. Due to scintillation the crosstalk will sometimes be above this signal power and sometimes below it, and for a given average (long term i.e. over different scintillation states arising from same scintillation pdf) received crosstalk power the fraction (again, let's call it F) of the time that the crosstalk is higher than the signal is straightforwardly again obtained from integrating the scintillation pdf with the appropriate $\mathrm{h}$ for a limit. In the case of such the systems that detect directly with constant thresholds and on-off keying as well as modulate irradiance, it leads to appearing error floors at high signal to noise ratios [27, 28]. There are claims that one can avoid them through adapting the thresholds. However, the recent research [10] pretends to provide an example of failure of such the approach. Specifically, the authors believe that there should be the error floor in the case of the adaptive threshold due to the following. In the case of the limit when there is no noise when the decision threshold is continuously adapted to the changing received power signal + crosstalk) it will be set at responsivity*(signal average power + crosstalk average power) [where the average is over data, but is changing depending on turbulence in either the signal case or the crosstalk case]. For that fraction of time that the crosstalk average power is bigger than the signal average power (regardless as to whether it is the signal or the crosstalk's turbulence that causes this) then the data on the crosstalk wavelength is always recovered in preference to the signal data. For scintillation states within this fraction (given by the earlier integration) the error probability ("BER") must then be 0.5 (as signal and crosstalk data uncorrelated so crosstalk "guesses" the signal half the time). When the more usual situation that the signal average power is bigger than the crosstalk average power (regardless as to which case i.e. whether it is the signal or the crosstalk's turbulence that causes this) then the data on the signal wavelength is always recovered in preference to the crosstalk data. For individual scintillation states within this fraction of time the error probability ("BER") is then each 0 . So we end up with an error floor for the average BER of $0.5 * \mathrm{~F}+0 *(1-\mathrm{F})=\mathrm{F} / 2$ where that average is over all states of scintillation for the pdf arising from one Rytov variance and $\mathrm{F}$ is the fraction of time during which the crosstalk is greater than the signal. If we introduce a small amount of noise into the system (say thermal noise (signal independent) for simplicity) that we will get deviations from this floor for lower signal powers but for sufficiently high signal powers this small amount of noise can be neglected and the error floor retained. However, there is the flaw in this argumentation. Particularly, from the definition of $\mathrm{F}$ it follows that the fact that BER equals $F / 2$ does not necessarily imply that BER does not depend on the received signal average power. Specifically, in [10], the first error floor that relies on OOK Modulation appears on Figure 2a in reference [10]. This illustration contains among others the dependences of BER on average received optical power in the three cases that are the following:

1. There is neither interferer nor turbulence (Si).

2. There is turbulence in the signal but there is no interferer (TurbuSi).

3. There is the interferer but the turbulence is present only in the signal (TurbuSi, XT).

However the error floor appears in other cases 4 and 5 but not correspond to reality. In Section 5, we present what one gets for these dependences. In Sections 6 and 7, we shed light on subtleties of the calculation and discuss the likely flaws that could lead to obtaining the plots that do not correspond to reality on the part of the authors of the reference [10] respectively. OOK can use either non-return-to-zero (NRZ) or return-to-zero (RZ) pulse formats. In NRZ-OOK, an optical pulse of peak power $\alpha_{e} P_{T}$ represents a digital symbol ' 0 'while the transmission of an optical pulse of peak power $P_{T}$ represents a digital symbol ' 1 ', $\mathrm{R}$ photo detector sensitivity. $\mathrm{T}_{\mathrm{b}}$ is the bit duration where average energy per bit $E_{b}$ is given by 15 .

$$
\begin{aligned}
& P_{e-b i t-o O K}=Q\left[\sqrt{\frac{E_{b}}{N_{0}}}\right] \\
& E_{b}=\frac{E_{P}}{2}=2\left(R_{P T}\right)^{2} T_{b}
\end{aligned}
$$

The electrical power spectral densities (PSDs) of OOK -NRZ and OOK-RZ with duty cycle $(\gamma=0.5)$ GIVEN by [15] seen FIG.1 (a).

$$
\mathrm{S}_{\text {OOK-NRZ }}(\mathrm{f})=\left(\mathrm{P}_{\mathrm{r}} \mathrm{R}\right)^{2} \mathrm{~T}_{\mathrm{b}}\left(\frac{\sin \pi \mathrm{f} \mathrm{T}_{\mathrm{b}}}{\pi \mathrm{f} \mathrm{T}_{\mathrm{b}}}\right)^{2}\left[1+\frac{1}{\mathrm{~T}_{\mathrm{b}}} \delta(\mathrm{f})\right]
$$


$\mathrm{S}_{\text {OOK-RZ }}(\mathrm{f})(\mathrm{f})=\left(\mathrm{P}_{\mathrm{r}} \mathrm{R}\right)^{2} \mathrm{~T}_{\mathrm{b}}\left(\frac{\sin \left(\pi \mathrm{f} \mathrm{T}_{\mathrm{b}} / 2\right)}{\pi \mathrm{f} \mathrm{T}_{\mathrm{b}} / 2}\right)^{2}\left[1+\frac{1}{\mathrm{~T}_{\mathrm{b}}} \sum_{\mathrm{n}=\infty}^{\infty} \delta\left(\mathrm{f}-\frac{\mathrm{n}}{\mathrm{T}_{\mathrm{b}}}\right)\right]$

where $\delta()$ is the Dirac delta function.

\subsection{EXAMPLE RESULT}

TABLE 1 KEY PARAMETERS USED IN THE CALCULATION [15].

\begin{tabular}{|c||c|c|}
\hline PARAMETER & DESCRIPTION & VALUE \\
\hline \hline P_avg & Average Optical Power & 1 \\
\hline \hline $\mathrm{R}$ & $\begin{array}{c}\text { Photo Detector } \\
\text { Sensitivity }\end{array}$ & 1 \\
\hline \hline$R_{b}$ & Data Rate & $2.5 \mathrm{~Gb} / \mathrm{ps}$ \\
\hline
\end{tabular}

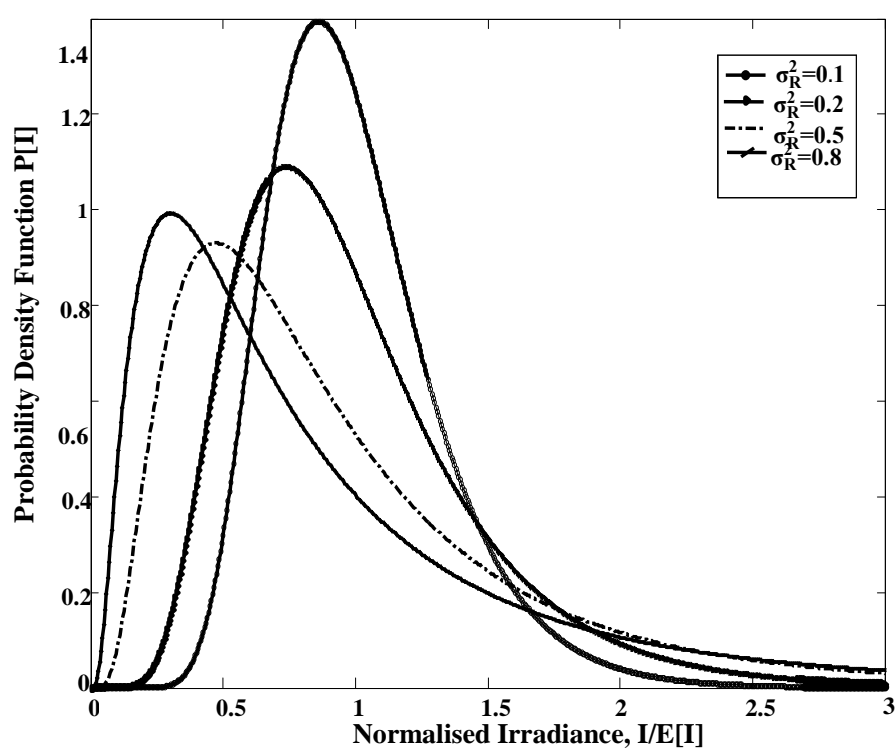

Figure. 2 Log-normal pdf with $\mathrm{E}[\mathrm{T}]=1$ for a range of log irradiance variance $o_{1}^{2}$.

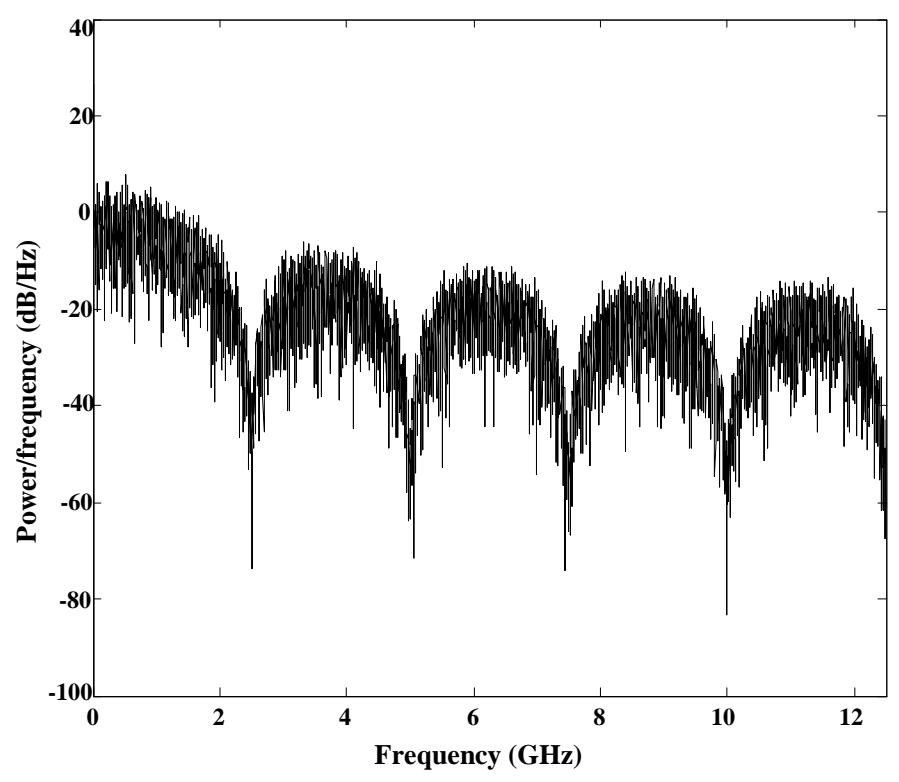

(a)

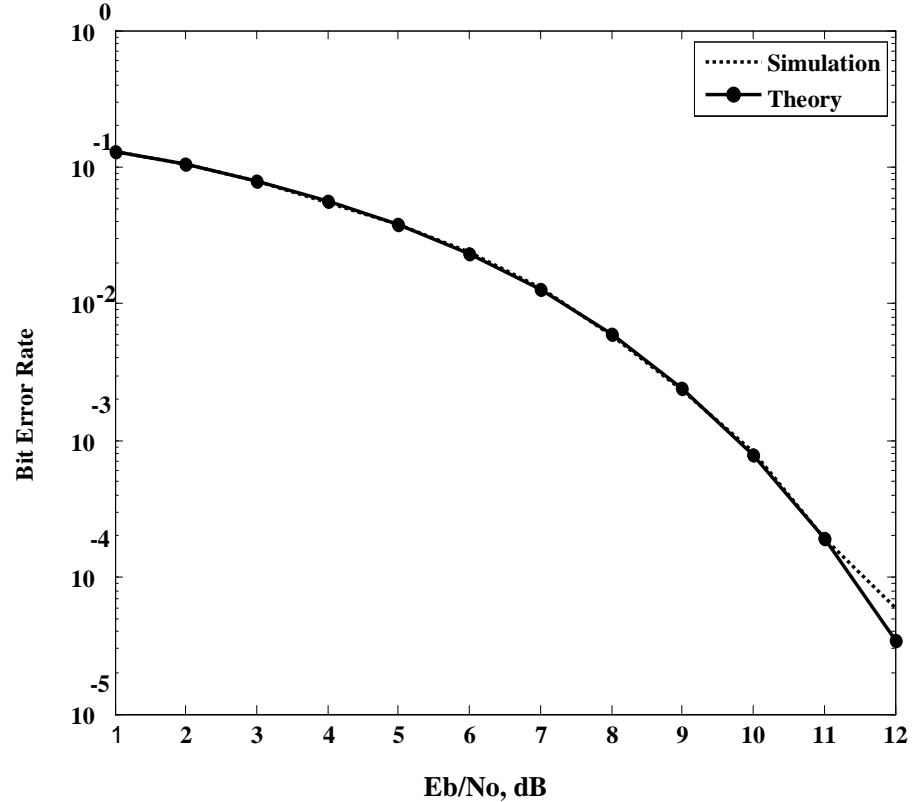

(b)

Figure 1 (a) PSD of TX signal (b) Bit error rate probability curve for OOK Modulation.

TABLE 2 PDF AND ERROR FLOOR EXPRESSIONS FOR VARIOUS TURBULENCE CHANNEL MODELS [15].

\begin{tabular}{|c|c|c|}
\hline $\begin{array}{l}\text { Turbulence } \\
\text { Models }\end{array}$ & PDF & Error Floors \\
\hline Lognormal & $\frac{1}{\sqrt{2 \pi} \sigma \mathrm{I}} \times \exp \left\{-\frac{\left(\operatorname{In} \mathrm{I}+\sigma^{2}\right)^{2}}{2 \sigma^{2}}\right\}$ & $\left(1-\mathrm{p}_{1}\right) \mathrm{Q}\left(\frac{\operatorname{InT}_{\text {th }}-\operatorname{In} \xi+\sigma^{2} / 2}{\sigma}\right)+p_{1} Q\left(\frac{\operatorname{In}(2+\xi)-\operatorname{InT}_{\text {th }}-\sigma^{2} / 2}{\sigma}\right)$ \\
\hline k-distribution & $\frac{2 \alpha^{\frac{\alpha+1}{2}}}{\Gamma(\alpha)} \mathrm{I}^{\frac{\alpha-1}{2}} \times \mathrm{K}_{\alpha-1}(2 \sqrt{\alpha \mathrm{I}})$ & $\left(1-p_{1}\right)\left\{1-\frac{1}{2}\right\}\left[\left[\mathrm{h}\left(1, \alpha, \mathrm{T}_{\mathrm{th}}, \xi\right)+\mathrm{h}\left(1, \alpha, \mathrm{T}_{\mathrm{th}}, \xi\right)\right]+\mathrm{p}_{1}\left\{\frac{1}{2}\left[\begin{array}{c}\mathrm{h}\left(1, \alpha, \mathrm{T}_{\mathrm{th}}, 2, \xi\right)+ \\
\mathrm{h} \xi\left(1, \alpha, \mathrm{T}_{\mathrm{th}}, 2, \xi\right)\end{array}\right]\right\}\right]$ \\
\hline Gamma-Gamma & $\frac{2(\alpha \beta)^{\frac{\alpha+\beta}{2}}}{\Gamma(\alpha) \Gamma(\beta)} I^{\frac{\alpha+\beta}{2}-1} \times \mathrm{K}_{\alpha-\beta}(2 \sqrt{\alpha \beta I}$ & $\left(1-p_{1}\right)\left\{1-\frac{1}{2}\right\}\left[\left[\mathrm{h}\left(\beta, \alpha, \mathrm{T}_{\mathrm{th}}, \xi\right)+\mathrm{h}\left(\beta, \alpha, \mathrm{T}_{\mathrm{th}}, \xi\right) \mathrm{p}_{1}\left\{\frac{1}{2}\left[\begin{array}{c}\mathrm{h}\left(\beta, \alpha, \mathrm{T}_{\mathrm{th}}, 2, \xi\right)+ \\
\mathrm{h}\left(\beta, \alpha, \mathrm{T}_{\mathrm{th}}, 2, \xi\right)\end{array}\right]\right\}\right]\right]$ \\
\hline $\begin{array}{l}\text { Negative } \\
\text { Exponential }\end{array}$ & $\frac{1}{\mu} \exp \left\{-\frac{I}{\mu}\right\}$ & $\left(1-p_{1}\right) \exp \left(\frac{T_{\text {th }}}{\mu \xi}\right)+p_{1}\left\{1-\exp \left[\frac{T_{\text {th }}}{(2+\xi) \mu}\right]\right\}$ \\
\hline
\end{tabular}




\subsection{AN ATTEMPT TO GET THE ERROR FLOOR \\ IN THE CASE OF ADAPTIVE THRESHOLD \\ NUMERICALLY}

\section{The Analysis:}

In what follows, we use the commonly used notations and present all values in SI units if not explicitly written otherwise. In the first case, the dependence is the following:

$\operatorname{BER}\left(P_{R, s i g}(1)\right)=\frac{1}{4} \operatorname{erfc}\left[\frac{2(\mathrm{r}-1) \mathrm{R} P_{R, s i g}(1) /(r+1)}{2 \mathrm{q} B_{e} R P_{R, s i g}(1)+\mathrm{o}_{\mathrm{th}}^{2}}\right]$

In the second one, it has the form

\subsection{OOK WITH UNOPTIMIZED DETECTION THRESHOLD}

The received signal $(r=\xi I+N)$ in the low state, where $\mathrm{N}$ and $I_{S}$ independent as written in [15].

$$
\begin{aligned}
& f\left(r / s_{o}\right)=\frac{1}{\xi} f_{1}\left(\frac{r}{\xi}\right) \times f_{N}(r) \\
& =\int_{0}^{\infty} \frac{1}{\sqrt{2 \pi \sigma_{x}}} \exp \left(-\frac{\left(\operatorname{In} \frac{x}{\xi}+\frac{\sigma^{2}}{2}\right)^{2}}{2 \sigma^{2}}\right) \\
& \times \frac{1}{\sqrt{2 \pi \sigma_{y}}} \exp \left(\frac{(r-x)^{2}}{2 \sigma_{y}^{2}}\right) d x
\end{aligned}
$$

$\mathrm{P}_{\mathrm{GG}}\left(\frac{\mathrm{P}}{P_{R, \operatorname{sig}}(1)}\right)=\frac{2(\alpha \beta)^{(\alpha+\beta) / 2}}{\Gamma(\alpha) \Gamma(\beta)}\left(\frac{\mathrm{P}}{P_{R, s i g}(1)}\right)^{\frac{(\alpha+\beta)}{2}-1} \begin{aligned} & \text { The Bit error rate (BER) for OOK using a fixed detection } \\ & \text { threshold } T_{t h} \text { as }\end{aligned}$

$$
\times \mathrm{K}_{\alpha-\beta}\left(2 \sqrt{\alpha \beta \frac{P}{P_{R, S i g}(1)}}\right)
$$

Finally, in the last case the dependence is the following

$$
\begin{aligned}
\mathrm{BER}=\frac{1}{4} \int_{0}^{\infty} & \operatorname{erfc}\left(\frac{2(r-1) R \times \frac{P\left(1-\left(1 / C_{X T}\right)\right)}{r+1}}{2 q B_{e} R \cdot P\left(1+\left(1 / C_{X T}\right)\right)+\sigma_{t h}^{2}}\right) \\
& \times P_{G G}\left(\frac{P}{P_{R, \text { sig }}(1)}\right) d p
\end{aligned}
$$

\begin{tabular}{|c|c|c|}
\hline PARAMETER & DESCRIPTION & VALUE \\
\hline$\lambda$ & Laser Wavelength & $1.55 \mu \mathrm{m}$ \\
\hline $\mathrm{Rb}$ & Data Rate & $2.5 \mathrm{Gbps}$ \\
\hline $\mathrm{r}$ & Extinction Ration & $10 \mathrm{~dB}$ \\
\hline$\eta$ & Q Quantum Efficiency & 1 \\
\hline $\mathrm{NF}$ & Amplifier Noise Figure & $1.77 \mathrm{~dB}$ \\
\hline$l_{\text {fso }}$ & FSO Length & $\begin{array}{c}2 \cong 3 \mathrm{Km}- \\
\text { Max }\end{array}$ \\
\hline$B_{o}$ & $\begin{array}{c}\text { Demux Channel } \\
\text { Bandwidth }\end{array}$ & $60 \times 10^{9}$ \\
\hline DRX & RCL Diameter & 0.017 \\
\hline$N_{o}$ & Single Polarization State & 0 \\
\hline$\overline{\mathrm{G}}$ & Opptical Amplifier Gain & $30 \mathrm{~dB}$ \\
\hline
\end{tabular}

The following values of the input parameters written in SI units are appropriate:

TABLE. 3 KEY PARAMETERS USED IN THE CALCULATION [10].

$$
P_{e}=\left(1-p_{1}\right) P_{F}+P_{1} P_{M}
$$$$
=\frac{\left(1-p_{1}\right) \exp \left(\frac{-\sigma^{2}}{8}\right)}{\sqrt{2 \pi \sigma}} \int_{0}^{\infty} \frac{\sqrt{\xi}}{x^{3 / 2}} \exp \left(\frac{-\operatorname{In}^{2} \frac{x}{\xi}}{2 \sigma^{2}}\right)
$$$$
\times\left(\frac{T_{t h-x}}{\sigma_{y}}\right) \mathrm{dx}+\frac{p_{1} \exp \left(-\frac{\sigma^{2}}{8}\right)}{\sqrt{2 \pi \sigma}} \int_{0}^{\infty} \frac{\sqrt{2+\xi}}{x^{3 / 2}}
$$$$
\times \exp \left(-\frac{\operatorname{In}^{2} \frac{x}{2+\xi}}{2 \sigma^{2}}\right) Q\left(\frac{X-T_{t h}}{\sigma_{y}}\right) d x
$$$$
=\frac{\left(1-p_{1}\right) \exp \left(\frac{-\sigma^{2}}{8}\right)}{\sqrt{2 \pi \sigma}} \int_{0}^{\infty} \frac{\sqrt{\xi}}{x^{3 / 2}} \exp \left(\frac{-\operatorname{In}^{2} \frac{x}{\xi}}{2 \sigma^{2}}\right)
$$$$
\times Q \sqrt{\gamma}\left(T_{t h-x}\right) d x
$$$$
+\frac{p_{1} \exp \left(-\frac{\sigma^{2}}{8}\right)}{\sqrt{2 \pi \sigma}} \int_{0}^{\infty} \frac{\sqrt{2+\xi}}{x^{3 / 2}} \times \exp \left(-\frac{I^{2} \frac{x}{2+\xi}}{2 \sigma^{2}}\right)
$$$$
\times Q \sqrt{\gamma}\left(T_{t h-x}\right) d x
$$

Where $T_{t h}$ is fixed detection threshold , the probability of flase alarm $P_{F}$ and probability of miss $P_{M}, Q_{(x)}=\frac{1}{\sqrt{2 \pi}} \int_{x}^{\infty} e^{-\frac{t}{2}} d t$ is the Gaussian Q-function, $\tilde{\mathrm{a}}=([I])^{2}$ or $\gamma=1 / N_{O}$ undfer normalized mean. 

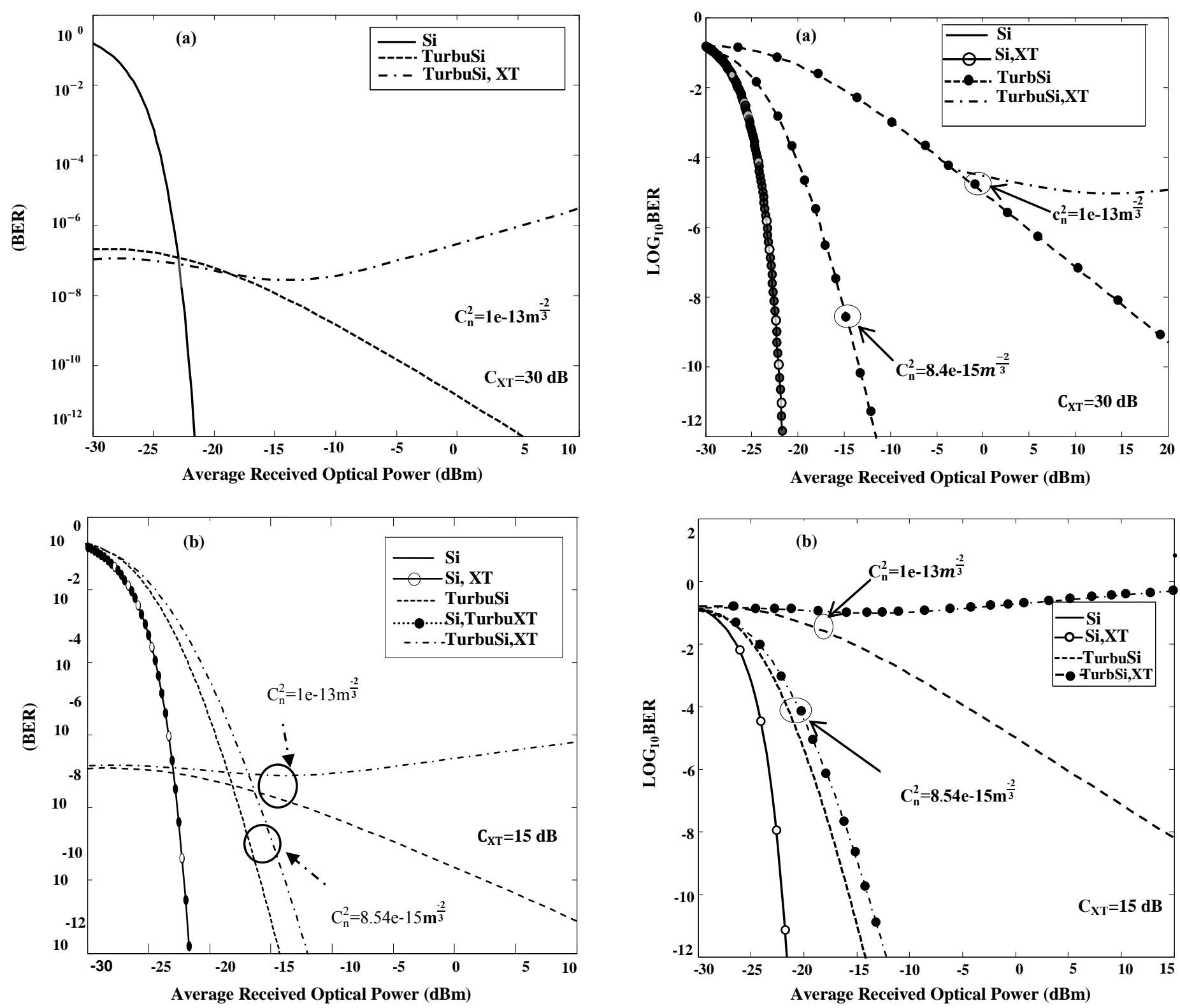

Figure.3 BER versus average received signal optical power $(\mathrm{dBm})$ for Turbulence regimes using OOK modulation (with amplifier) with crosstalk (a) $\mathrm{C}_{\mathrm{XT}}=30 \mathrm{~dB}$, (b) $\mathrm{C}_{\mathrm{XT}}=15 \mathrm{~dB}$
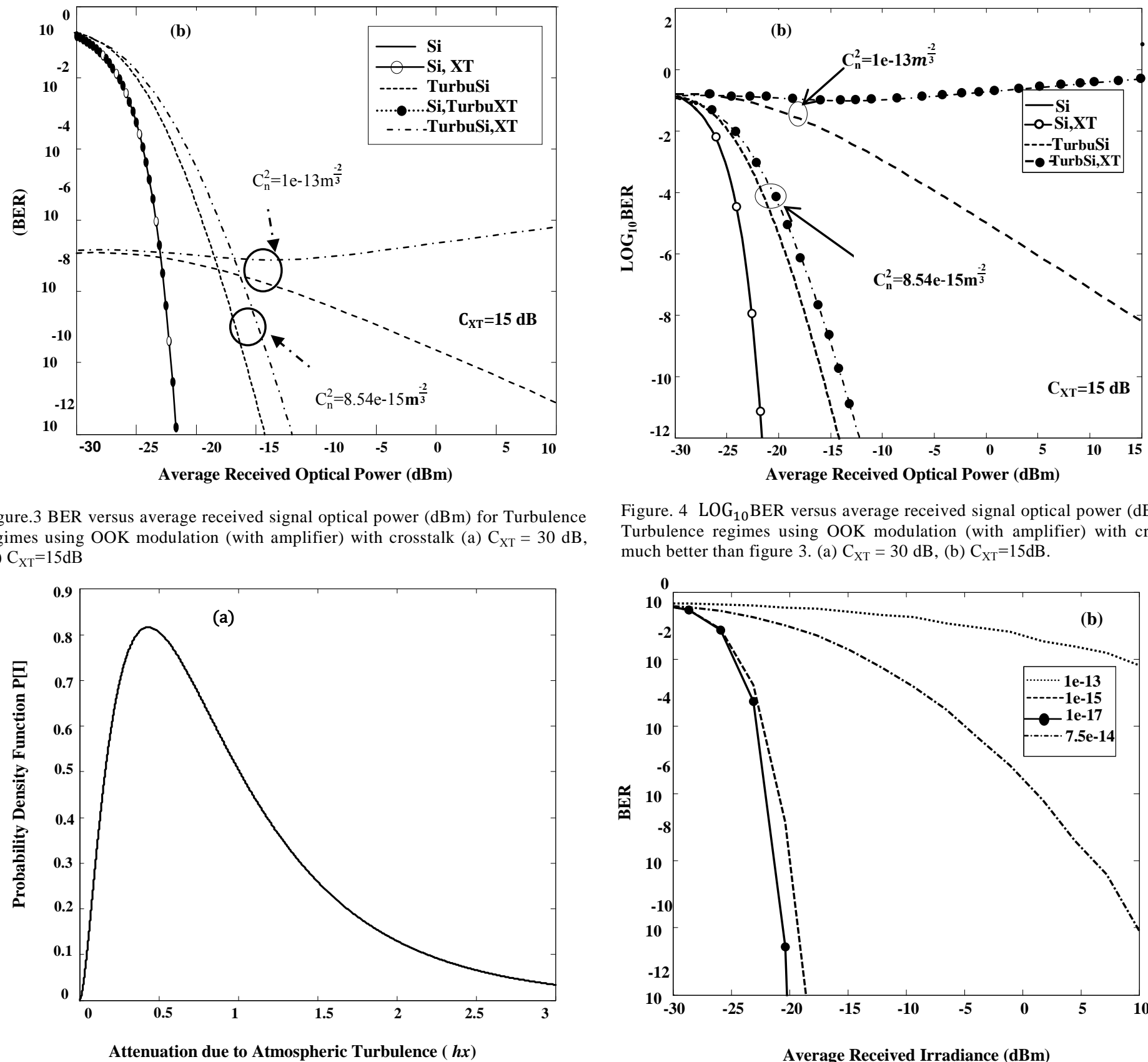

Figure. $4 \mathrm{LOG}_{10}$ BER versus average received signal optical power $(\mathrm{dBm})$ for Turbulence regimes using OOK modulation (with amplifier) with crosstalk much better than figure 3. (a) $\mathrm{C}_{\mathrm{XT}}=30 \mathrm{~dB}$, (b) $\mathrm{C}_{\mathrm{XT}}=15 \mathrm{~dB}$.

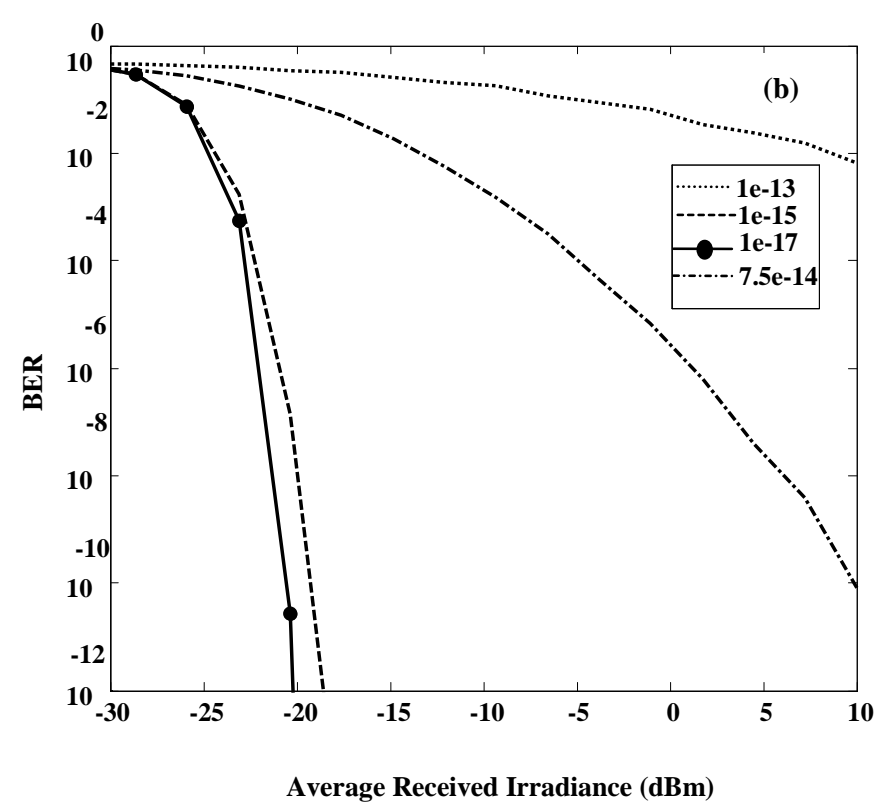

Figure. 5 (a) Attenuation due to Atmospheric $\left(h_{x}\right)$, (b) Bit Error Rare against \% Average Received Irradiance (dBm) for $C_{n}^{2}\left(m^{-2 / 3}\right)$ in weak and strong turbulence. 
TABLE. 5 ATMOSPHERIC ATTENUATION COEFFICIENT $\alpha$

Figure 1(a) shows given value of P OOK-RZ a $=0.5$ has twice the ratio $E_{b} / N_{0}$ compared with OOK-NRZ, to achieve the same error performance, OOK-RZ, ã $=0.5$ requires $3 \mathrm{db}$ less electrical power or $1.5 \mathrm{~dB}$ less average optical power compared with OOKNRZ. In FIG.2, The log-normal pdf is plotted for different values of log-irradiance variance of $o_{1}^{2}$. As the value of $o_{1}^{2}$ increases, the distribution becomes more skewed with tails in the infinity direction there are fluctuation of the irradiance. Figure 3 depicts the results of our calculations. As one can see, there is no error floor in the case \#3of that relies on OOK-modulation. Therefore, it is worthwhile to examine the adequacy of the calculations. The error floor occurs in case non-turbulent signal with turbulent interferer $(\mathrm{Si}$, TurbuXT) at much lower cause the add/drop of demux channel which reduced power of turbulent interferer. The floor starts once the signal power and crosstalk are sufficiently large that the noises are very unlikely to cause a reverse threshold crossing. In FIG.3(a) show the first three cases BER floor only and not accentuated error floor in case of ( $\mathrm{Si}$, Turbulent) with crosstalk signal to crosstalk ratio $30 \mathrm{~dB}$, while presented in FIG3.a the three first three cases only of BER floor with OOK. In the weak Turbulent (WT) the error floor occurs at lower BER from range found using signal to crosstalk ratio $30 \mathrm{~dB}$ and $15 \mathrm{~dB}$. While in FIG.3 (b) obtained of all cases of error floor and but not corresponding with reality and calculated a value the result of the total OLT Receiver $\sigma_{\mathrm{th}}^{2}$ is the summation of ASEshot noise, signal-ASE beat and signal shot noise with with analysis numerical where the total OLT receiver noise variance $o_{t h}^{2}=$ $2 m t R^{2} N_{0}^{2} B_{O} B_{e}, m t$ is the number of a polarization states of amplifies spontaneous emission ASE $(\mathrm{mt}=2), \mathrm{R}=\eta \mathrm{q} / \mathrm{E}$ is the responsivity in $(\mathrm{A} / \mathrm{W}) . \mathrm{E}=\mathrm{h} f c$ is photon energy and $\mathrm{h}$ is plank's constant. (An integrate-and-dump receiver is assumed at the decision circuit with electrical bandwidth $B_{e}=1 / 2 T_{b}, T_{b}=1 / 2 R_{b}$ and $\mathrm{Rb}$ is the data rate, $\mathrm{Be}=\mathrm{Rb} / 2$, Using the equations we calculate the result of the total OLT Receiver $\left(\sigma_{\mathrm{th}}^{2}=98 \times 10^{-14}\right)$. The provided expression relates in $[10]$ to the case when there is no noise. It implies that the denominator of the right hand side of the equation (6) [10] is zero. As for the numerator, in the case of the signal with turbulence and interferer with no turbulence when there is no amplifier (FIG. 2a) in paper [10] it is the following: $(2 \mathrm{R} *(\mathrm{r}-1) /(\mathrm{r}+1)) *(\mathrm{PR}$, sigPint) where Pint is a positive constant. Therefore, from the shape of the erfc function it follows that BER $=0$ only when $P R$, sig>Pint. Since in the respective case of the signal with turbulence when there is no interferer Pint $=0$, it is easier to reach the error floor in the second case (the one when there is no interferer). The result analysis of all noises and interchannel crosstalk are obtained for all cases and calculated values $\alpha$ and $\beta$ is effective attenuation of number of large-scale eddies of the scattering process, value $\alpha=5.1881$ and Beta is the effective number of small-scale eddies of the scattering process $\beta=4.9917$, this mean that Trublence regime is a weak causes the interference and interchannel-crosstalk as shown in Table 4 [15].

In the Turbulence which emerged-interchannel crosstalk. Pinst,sig ( hsig) is the instantaneous received signal power thus Pinst,sig (1) is also turbulence free average received power (TrblncFrP) of the input signal at the optical preamplifier which get a value of calculation using algoritm in matlab ,TRblncFRP= 1.1249e-006dBm. In TABLE 4, shows Atmospheric Attenuation Coefficient $\alpha$ in weather condition.

TABLE. 5 TRUBLENCE REGIME OF FADING STRENGTH PARAMETER FOR GAMMA-GAMMA TURBULENCE MODEL.

\begin{tabular}{|c|c|c|c|}
\hline Parameter & Weak & Moderate & Strong \\
\hline$\sigma_{\mathrm{R}}^{2}$ & 0.2 & 1.6 & 3.5 \\
\hline á & 11.6 & 4.0 & 4.2 \\
\hline$\hat{\mathrm{a}}$ & 10.1 & 1.9 & 1.4 \\
\hline
\end{tabular}

\begin{tabular}{|c|c|}
\hline Weather condition & $\alpha$ \\
\hline \hline Very Clear & $0.48 \mathrm{~dB} / \mathrm{km}$ \\
\hline \hline Light Fog & $13 \mathrm{~dB} / \mathrm{km}$ \\
\hline \hline clear & $0.96 \mathrm{~dB} / \mathrm{km}$ \\
\hline \hline Dense fog & $73 \mathrm{~dB} / \mathrm{km}$ \\
\hline \hline Haze & $2.8 \mathrm{~dB} / \mathrm{km}$ \\
\hline \hline Deep Fog & $309 \mathrm{~d} / \mathrm{km}$ \\
\hline
\end{tabular}

\subsection{SUBTLETIES OF THE CALCULATIONS}

The major challenge consists in taking integrals in the right hand sides of the equations (16) and (17) properly. To find correct values for the integral limits in these equations, one should examine the dependences that is the following:

$$
\begin{array}{r}
\mathrm{BER}=\frac{1}{4} \int_{0}^{\infty} \operatorname{erfc}\left[\begin{array}{c}
\left(\frac{2(\mathrm{r}-1) \cdot \mathrm{R} \times \mathrm{P} /(\mathrm{r}+1)}{2 \mathrm{q} \mathrm{B}_{\mathrm{e}} \mathrm{R} \cdot \mathrm{P}+\sigma_{\mathrm{th}}^{2}}\right) \\
\times\left[\frac{\mathrm{P}}{\mathrm{P}_{\mathrm{R}, \mathrm{sig}}(1)}\right] d p
\end{array}\right] \\
\mathrm{BER}=\frac{1}{4} \int_{0}^{\infty} \operatorname{erfc}\left[\begin{array}{c}
\left(\frac{2(\mathrm{r}-1) \cdot \mathrm{R} \times \frac{\mathrm{P}\left(1-\left(1 / \mathrm{C}_{\mathrm{XT}}\right)\right)}{\mathrm{r}+1}}{2 \mathrm{qB} \mathrm{B}_{\mathrm{e}} \mathrm{R} \cdot \mathrm{P}\left(1+\left(1 / \mathrm{C}_{\mathrm{XT}}\right)\right)+\sigma_{\text {th }}^{2}}\right) \\
\times \mathrm{P}_{\mathrm{GG}}\left[\frac{\mathrm{P}}{\mathrm{P}_{\mathrm{R}, \mathrm{sig}}(1)}\right] d P
\end{array}\right]
\end{array}
$$

$$
\mathrm{P}_{\mathrm{GG}}\left(\mathrm{h}_{\mathrm{X}}\right)=\frac{2(\alpha \beta)^{(\alpha+\beta) / 2}}{\Gamma(\alpha) \Gamma(\beta)} \mathrm{h}_{\mathrm{X}}^{(\alpha+\beta) / 2-1 \mathrm{~K}_{\alpha-\beta}\left(2 \sqrt{\alpha \beta \mathrm{h}_{\mathrm{X}}}\right)}
$$

where $h_{X}$ is the attenuation due to atmospheric turbulence.

Since

$$
\int_{10^{-12}}^{3} P_{G G}\left(h_{x}\right) d h x=0.9725,
$$

performing integrations in the equations (16) and (17) from $10^{-12} \mathrm{P}_{\mathrm{R} \text {,sig }}(1)$ to $3 . \mathrm{P}_{\mathrm{R}, \text { sig }}(1)$ one can count on the accuracy that does not exceed a few percent. Figure 5(a) is the plot of the dependence of gamma-gamma probability density on $h x$. On this plot $h x$ changes from $10^{-12}$ to 3. From FIG.5 (a), it follows that on this interval there are no regions of high gradients of $P_{G G}$. Therefore, one can use a uniform grid performing integrations. To obtain Figure 3 we cover the range of $P$ from $10^{-12}$

$P_{R, \text { sig }}(1)$ to $3 \cdot P_{R, \text { sig }}(1)$ to with the uniform grid that consists of 72001 nodes. To figure out whether it is enough, we perform the same calculations on the uniform grid that consists of 36001 nodes and calculate the percentage of the maximal deviation. Both in Case 2 and Case 3, the deviations are much lower than $1 \%$. Hence, the chosen grid is dense enough. Remarkably, conducting a numerical experiment we arrived at the dependencies of BER on average received optical power for three above mentioned cases that match the ones presented in [6] much better than FIG. 3 does (see FIG.4). FIG.5 (b) shows the BER performance is plotted as a function of Average Received Irradiance $(\mathrm{dBm})$ for $C_{n}^{2}$ at different levels of atmospheric turbulence. Expectedly, the Average Received Irradiance $(\mathrm{dBm})$ increases as the turbulence strength 
increases.

\subsection{What Could Mislead The Researches}

The description of the experiment is the following. One can take advantage of the uniform grid with 20001 nodes and choose for the lower limit in the integrals the value which is close to 0 whereas for the upper one the value which is much greater than the first number. For instance, one can try $10^{-12}$ for the lower limit and $10^{-3}$ for the upper one. However, the arbitrary choice of limits can lead to the normalization of the gamma-gamma probability density function that does not equal to 1 exactly. Therefore, one can introduce the normalization constant $A$ in this function:

$\mathrm{P}_{\mathrm{GG}}\left(\frac{\mathrm{P}}{\mathrm{P}_{\mathrm{R}, \mathrm{sig}}(1)}\right)=\left[\begin{array}{c}\frac{2(\alpha \beta)^{(\alpha+\beta) / 2}}{\Gamma(\alpha) \Gamma(\beta)}\left(\frac{\mathrm{P}}{\mathrm{P}_{\mathrm{R}, \mathrm{sig}}(1)}\right)^{\frac{(\alpha+\beta)}{2}-1} \\ \times \mathrm{K}_{\alpha-\beta}\left(2 \sqrt{\alpha \beta \frac{\mathrm{P}}{\mathrm{P}_{\mathrm{R}, \mathrm{sig}}(1)}}\right)\end{array}\right]$ (27)

From Figure 2a of the reference [10], it follows that the values of $\log _{10}(B E R)$ at the average received optical power equal to -30 $\mathrm{dBm}$ coincide in Cases 1 and 2. Hence, one can perform calculations assuming that the constant $A$ presented in the equation (14) is equal to 1 and estimate its correct value as $10^{\Delta}$ where $\Delta$ is equal to $\left(\log _{10}(\mathrm{BER}) \mid \mathrm{P}_{\mathrm{R}, \operatorname{sig}(1)}\right)=30 \mathrm{dBm}$ in Case 1 minus such the value one obtains in Case 2 assuming that $C_{n}^{2}=10 e^{-13} m^{\frac{-2}{3}}$. We plotted the curve presented on Figure 3 that corresponds to Case 2 and $C_{n}^{2}=8.4 e^{-15} m^{\frac{-2}{3}}$ using the same value of $\Delta$. Since on Figure 4 of a) and b) the values of $\log _{10}(B E R)$ at the average received optical power equal to $-30 \mathrm{dBm}$ coincide in Cases 1 and 2, one can assert that the integration limits used in the equations (16) and (17) and the increment are properly chosen. However, the drawback of this experiment consists in ignoring the degree of deviation of $A$ from 1. Obviously, it cannot exceed few percent if one strives to obtain the curves that correspond to reality.

\section{MODELING OF HYBRID WDM-DWDM-PON/FSO With DPPM.}

5.1 WDM-DWDM-PON/FSO architecture as shown in FIG.6

A. Optical Line Terminal (OLT)

B. Wave Division Multiplexing and dense wavelength division multiplexing passive optical network free space optics(WDM-DWDM-PON/FSO) $\left(L_{\text {mux }}\right),\left(L_{\text {demux }}\right)$

C. Optical Amplifier Placement

D. Feeder Fibre

E. Free space optical communications

F. Optical Network Unit

The optical line terminator is one of the most important at the network. It provides an interface between core network and PON network. Wave division multiplexing and dense wavelength division multiplexing passive optical network free space optics (WDM-DWDM-PON/FSO) (technology is a key component of next generation requirements designed and simulated to serve as long reach passive optical network (LR-PON) for achieving higher data rate, huge capacity, and enables operators to deliver high bandwidth to multiple using one wavelength of upstream transmission and another wavelength for upstream transmission. Optical amplifier placement with two different sources of amplifier location are Case A at the remote node and at the OLT Case B. Case $A$ in the upstream attenuation of feeder fibre causes amplified spontaneous emission noises(ASE). and Case B loss of
OLT demux causes ASE. Feeder fibre $20 \mathrm{Km}$ between Case A and Case B ONU is access services.

\subsection{WDM DPPM CROSSTALK MODELING}

WDM DPPM system, is simple case of a single adjacent interferer However, the analysis accentuated interchannel crosstalk, where , M bits at the raw data rate $\mathrm{R}_{\mathrm{b}}$, are assigned to a frame, where each block of $b$ bits is mapped to one of $\mathrm{M}$ possible symbols $\left(\mathrm{s}_{0}, s_{1}, s_{\mathrm{m}}\right)$ where $\mathrm{n}=2^{\mathrm{M}}$ equal-sized time slots $\mathrm{t}_{\mathrm{s}}=\mathrm{MT}_{\mathrm{b}} / \mathrm{n}$, where $\mathrm{T}_{\mathrm{b}}=1 / \mathrm{R}_{\mathrm{b}}, \mathrm{t}_{\mathrm{s}}=\mathrm{M} /$ $\mathrm{nR} b$, where $\mathrm{M}$ is referred to as the coding level. For example, at the binary data rate of $2.5 \mathrm{~Gb} / \mathrm{ps}$, the DPPM frames for $\mathrm{M}=2$ contain four slots, $\mathrm{t}_{\mathrm{s}}=2 \mathrm{~T}_{\mathrm{b}} / 4, \mathrm{ts}=2 / 4 \times 2.5 \mathrm{GHz}=1 / 5 \mathrm{GHz}$, each and thus the pulse in each frame represents a 2-bit word transmitted at a slot rate of $5 \mathrm{GHz}$. For $\mathrm{M}=4$ contain= 16 slots example of time waveforms of an (OOK-NRZ) and e quivalent 16-DPPM signal $(M=4)$ [20]. Systems the bandwidth expands with increasing coding level and appropriate spacing is required between the wavelengths for systems with high coding level, optical signals include not only data signal but also background noise and interferer signal with the average powers of background power $\mathrm{P}_{b}$ and and power transmitter $P_{t}$ int. The means and variances of the random variables, both are representing the integration over the slot that contains only the signal pulse, only crosstalk pulse, both signal and crosstalk pulses and no pulses (i.e. empty slot) are derived and, respectively, written as $[13,15]$.

$\mu_{\mathrm{X}_{\text {sigint }}}\left(\mathrm{h}_{\mathrm{d},} \mathrm{h}_{\mathrm{i}}\right)=\frac{\operatorname{LRqN}_{\mathrm{o}}}{\mathrm{t}_{\mathrm{s}}}+\mathrm{Gq}\left(\operatorname{sigRP}_{\mathrm{d}}\left(\mathrm{h}_{\mathrm{d}}\right)+\operatorname{int} \mathrm{R}_{\mathrm{i}} \mathrm{P}_{\mathrm{i}}\left(\mathrm{h}_{\mathrm{i}}\right)\right)$

$o_{x_{s i g, i n t}}^{2}\left(h_{d}, h_{i}\right)=\left(\begin{array}{c}\mathrm{o}_{t h}^{2}+\left(\frac{\left(L R q^{2} N_{O}\right)}{t_{s}^{2}}\right) \\ +G q^{2}\left[\left(R+2 R^{2} N_{o}\right) \frac{\operatorname{sig} P_{d}\left(h_{d}\right)}{t_{s}}\right] \\ +\left(R_{i}+2 R_{i}^{2} N_{o, i}\right) \frac{\operatorname{int} P_{i}\left(h_{i}\right)}{t_{s}}\end{array}\right)$

where sig/int $=0$ or 1 depending on the presence of signal/crosstalk pulse in slot. $o_{t h}^{2}$ is the DPPM thermal noise variance, $\mathrm{R}=c ̧ / h$, $\mathrm{R}_{\mathrm{i}}=c ̧ / h_{i}^{\prime}{ }_{i}$, ç is the PD quantum efficiency, $\mathrm{q}$ is the electron charge, $\mathrm{L}=\mathrm{B}_{\mathrm{O}} \mathrm{m}_{\mathrm{t}} \mathrm{t}_{\mathrm{S}} \mathrm{L}=\mathrm{B}_{\mathrm{O}} \mathrm{m}_{\mathrm{t}_{\mathrm{S}}}$ is the product of spatial and temporal modes [13], $\mathrm{B}_{\mathrm{O}}$ is the demux or OBPF channel bandwidth, and $\mathrm{mt}$ is the number of ASE noise polarisation states.

The means and variances have been derived with modifications to account for crosstalk- ASE beat noise assuming the interferer and the desired signal experiences the same ASE noise at the amplifier output [15].

$$
P_{\text {we }(1, r)}\left(h_{d}, h_{i}\right) \geq \prod_{\substack{j=1 \\ j=\text { sig slot }}}^{n} P\left(X_{1, \text { int }}>\left(X_{j} \mid h_{d}, h_{i}\right)\right)
$$

where $\mathrm{X}_{\mathrm{j}}$ represents the content of the non-signal slot $\mathrm{X}_{0}$,int, and

$$
\begin{gathered}
\mathrm{P}_{\text {we }(l, \mathrm{r})}\left(\mathrm{h}_{\mathrm{d}}, \mathrm{h}_{\mathrm{i}}\right) \geq 1-\left(1-\mathrm{P}\left(\mathrm{X}_{0,0}>\mathrm{X}_{1, \mathrm{int}} \mid\left(\mathrm{h}_{\mathrm{d}}, \mathrm{h}_{\mathrm{i}}\right)\right)^{\mathrm{n}-1-(l-\mathrm{r}}\right. \\
\times 1-\mathrm{P}\left(\mathrm{X}_{0,1}>\mathrm{X}_{1, \text { int }} \mid\left(\mathrm{h}_{\mathrm{d},} \mathrm{h}_{\mathrm{i}}\right)\right)^{(l-\mathrm{r})}
\end{gathered}
$$




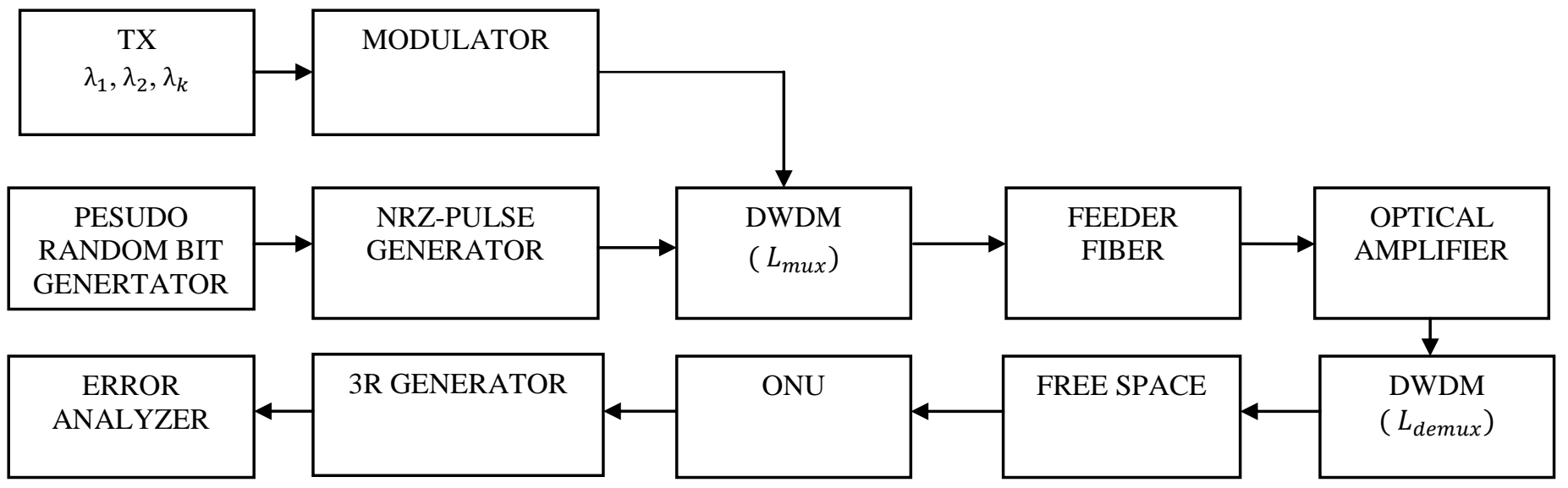

(a)
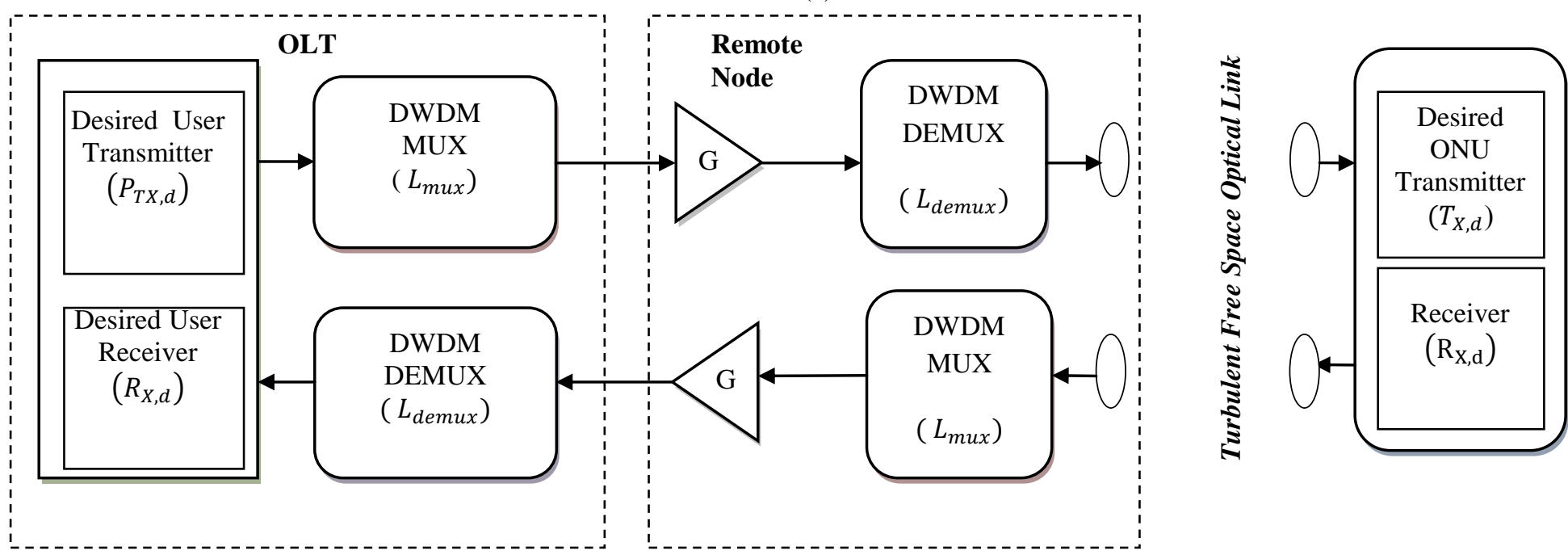

(b)

Upstream Transmission

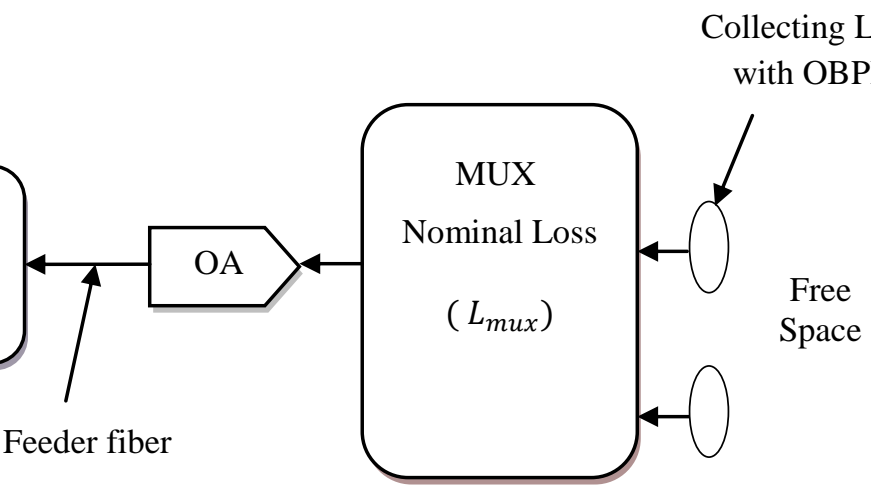

(c)

Desired ONU

Transmitter

$\left(T_{X, d}\right)$

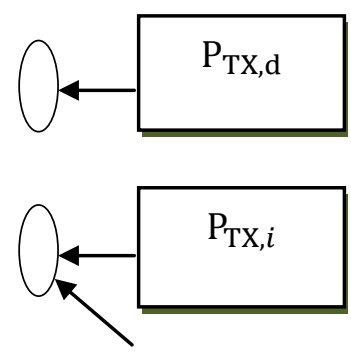

Transmitting Lens

\section{Downstream Transmission}

Desired User Transmitter (Tx, d)

Transmitting

Lens

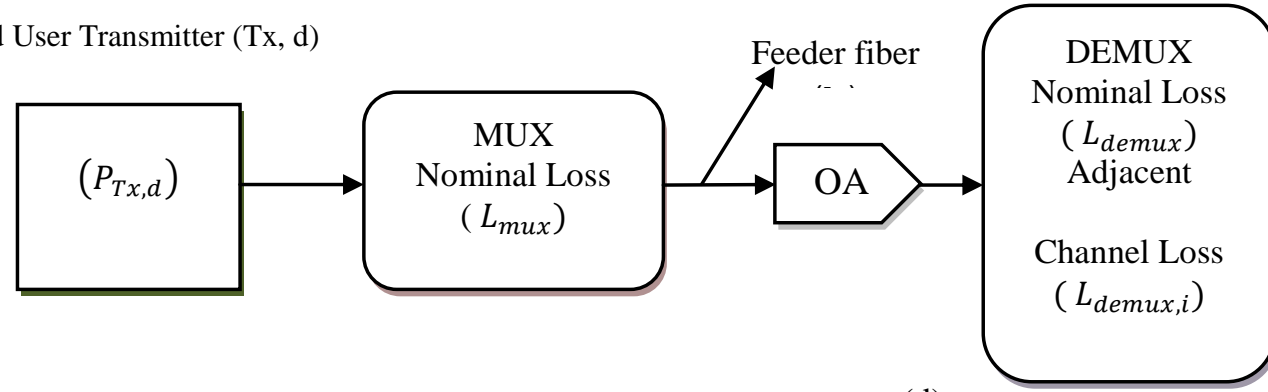

(d)

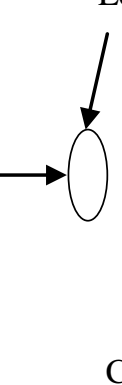

Collecting Lens with OBPF 

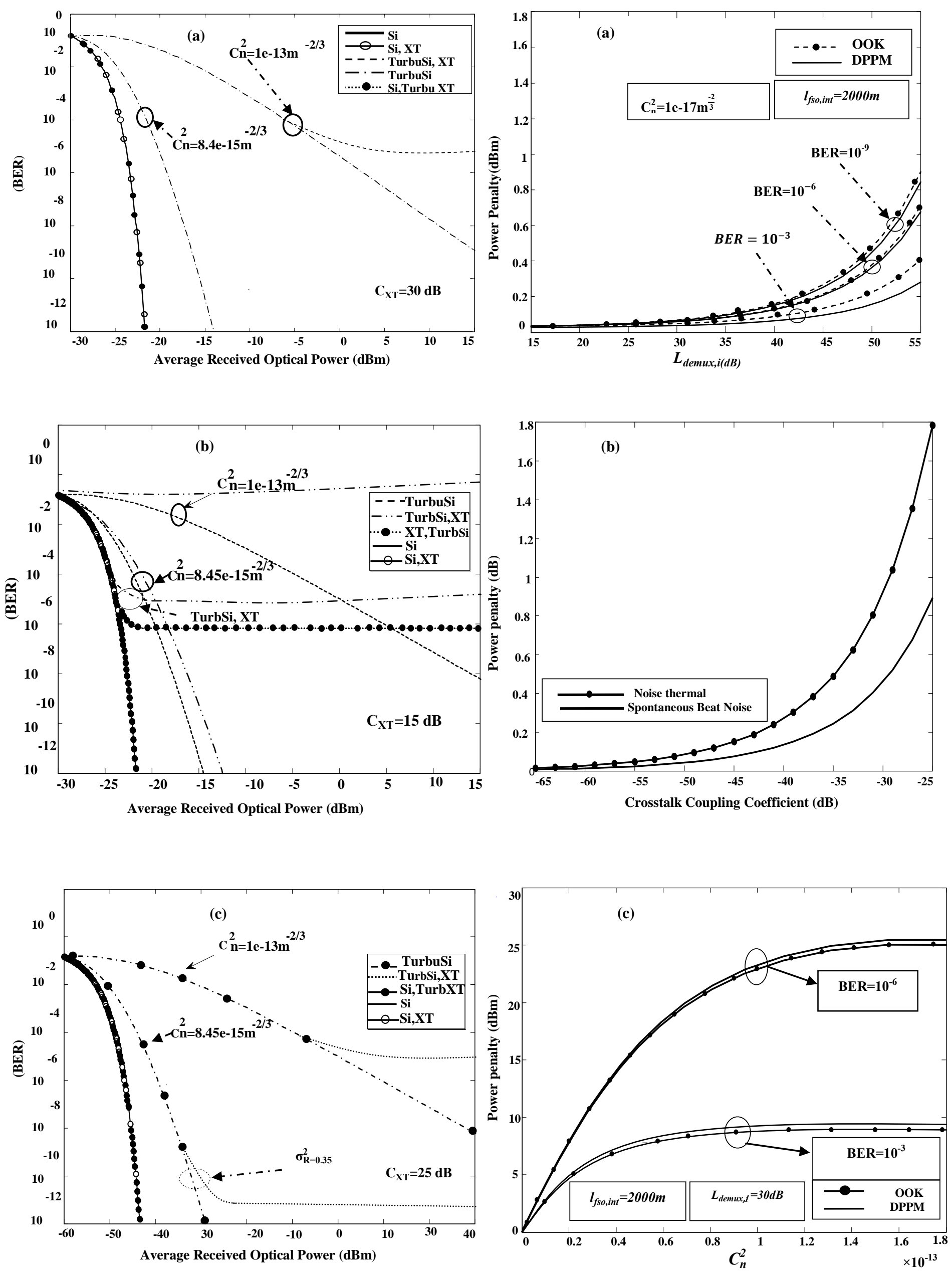

Figure. 7 BER versus average received signal optical power (dBm) for WT and ST (no amplifier) with DPPM crosstalk ( a) $\mathrm{C}_{\mathrm{XT}}=30 \mathrm{~dB}$, (b) $\mathrm{C}_{\mathrm{XT}}=15 \mathrm{~dB},(\mathrm{c}) \mathrm{C}_{\mathrm{XT}}=25 \mathrm{~dB}$.

Figure. 8 Power penalty vs (a) interferer demux channel rejection $L_{d e m u c, i}$ at $l_{f s o}=1500$ meter $(\mathrm{b})$ crosstalk coupling coefficient (dB) (c) Refractive index structure $C_{n}^{2}$. 

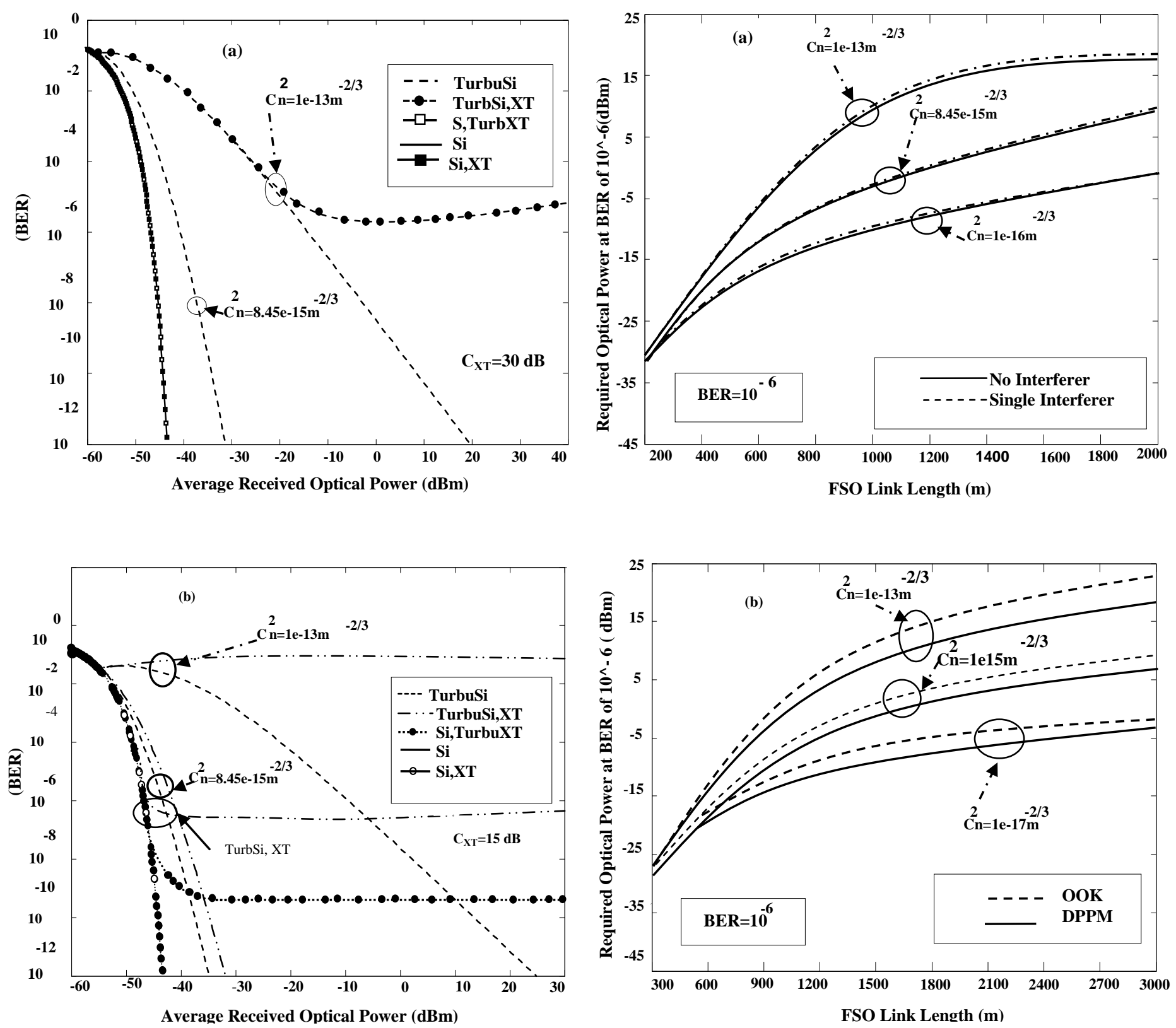

Figure. 9 BER versus Average Received Signal Optical Power (dBm) for WT and ST (with amplifier) with DPPM crosstalk (a) CXT $=30 \mathrm{~dB}$, (b) $=$. CXT $=15 \mathrm{~dB}$.

Figure. 10 Required optical power $(\mathrm{dBm})$ verses $l_{f s o}$ link length (m), for ST and WT at (a) Ldemux, $\mathrm{i}=30 \mathrm{dBm}$, lfso $=2000$ meter, (b) lfso $=3000$ meter, Ldemux, $\mathrm{i}=35 \mathrm{dBm}$.
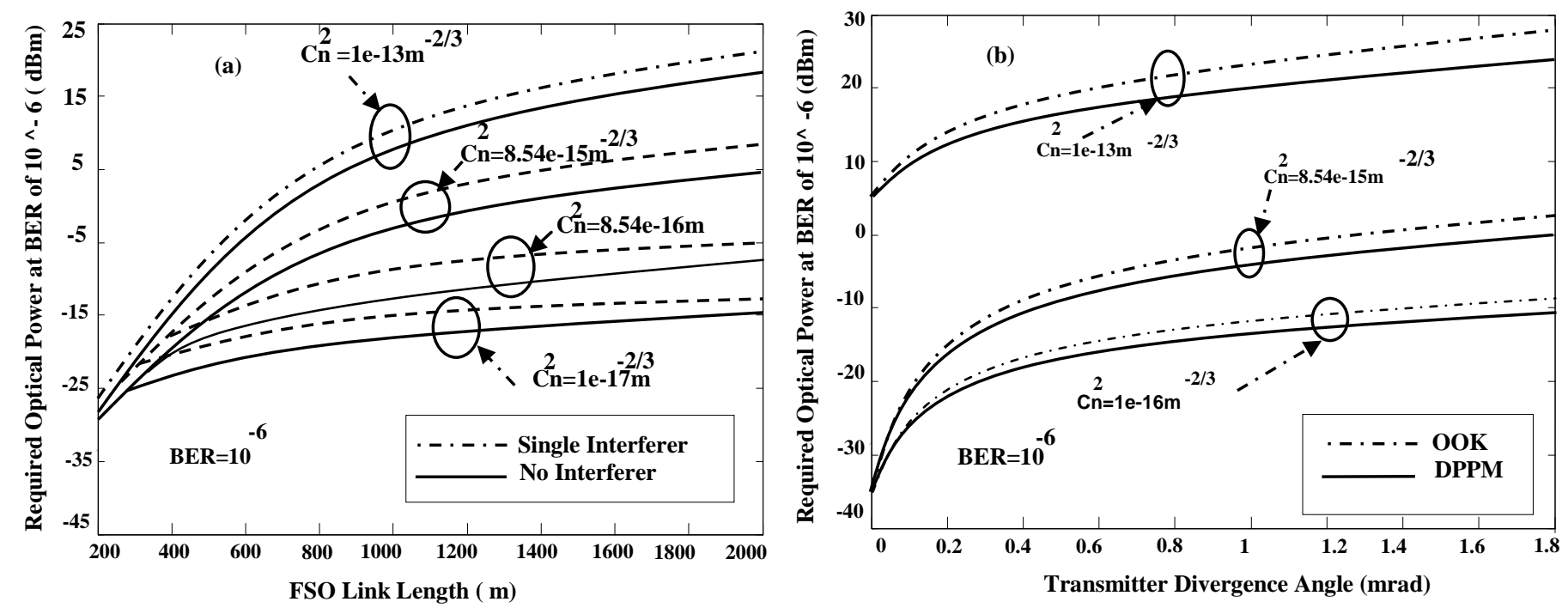

Figure.11 Required optical power $(\mathrm{dBm})$ for ST and WT, at Ldemux,i $=15 \mathrm{dBm}$, (a) lfso $=2000$ meter, (b) Ldemux, $\mathrm{i}=15$, Transmitter divergence angle $(\mathrm{mrad}) \theta_{\mathrm{XT}}=0.2 \mathrm{mrad}$. 
It can be see the result [FIG.7 (non amplified case) with DPPM crosstalk for (a) $C_{X T}=30$, (b) $C_{X T}=15$ (c) $C_{X T}==25$, the error floor occurs in all cases 1) no, interferer, no turbulence (Si); 2)signal with turbulence, no interferer (TurbuSi); 3) signal with turbulence, interferer with no turbulence (TurbuSi, XT ); 4) signal with interferer, no turbulence ( $\mathrm{Si}, \mathrm{XT}$ ); and 5) signal with no turbulence, interferer with turbulence ( $\mathrm{Si}$, Turbu XT). With DPPM of WDM/FSO accentuated error floor corresponding to the reality unlike OOK no error floor or may not reality. To under the error floor of turbulence accentuation. The case of ( $\mathrm{Si}$, TurbuXT) can increase to 1 value so \{crosstalk become 1 , data 0 \} is greater than \{crosstalk 0 , data 1 \} when $h_{\text {int }}$ is higher from $h_{\text {sig }}$, when value a data rate is faster from turbulence leading to error this occur when $\mathrm{h}_{\text {int }}>\mathrm{h}_{\text {sig. }}$. In case of the (TurbuSi, XT) same case (Si,TurbuSXT) except a time of the point attenuation of the signal. The error floor occurs when turbulence has increases the interfering $h_{\text {int }}>h_{\text {sig }}$. The times of crosstalk power is bigger than the signal power cause the turbulent, there is a perfect detection of crosstalk of BER., for the signal, so the error floor is simply given by $0.5 \times$ Prob (crosstalk power $>$ signal power). FIG. 8 show Power penalty vs. (a) interferer demux channel rejection $L_{\text {demux }, i}$ at $l_{\text {fso }}=1500$ meter $(\mathrm{b})$ crosstalk coupling coefficient (dB) (c) Refractive index structure $C_{n}^{2}$. FIG.8 (a) the power penalty for the DPPM system be lower than OOK in weak turbulence for $\mathrm{C}_{\mathrm{n}}^{2}=1 \mathrm{e}-17 \mathrm{~m}^{-2 / 3}$. It is seen that the DPPM require lower power than OOKFOR all values of $\boldsymbol{C}_{\boldsymbol{n}}^{2}$. FIG.8 (b) represented crosstalk coupling coefficient against the power penalty. It is seen that the power penalty that dominated by thermal noise higher than the power penalty that dominated spontaneous beat noise. The optical received signal spontaneous more accurate than optical received signal by thermal noise. FIG.8 (c) indicate that the power penalty results of the OOK system has lower power penalty than DPPM in moderate and strong turbulence for $\mathrm{C}_{\mathrm{n}}^{2}=1 \mathrm{e}-13 \mathrm{~m}^{-2 / 3}$. FIG.9 (a) and (b) indicate of BER versus Average Received Signal Optical Power $(\mathrm{dBm})$ for WT and ST (with amplifier) with DPPM crosstalk (a) $\mathrm{CXT}=30 \mathrm{~dB},(\mathrm{~b})=. \mathrm{CXT}=15 \mathrm{~dB}$. The result indicate $\mathrm{n}$ FIG.9 that the error floor occurred at a much lower BER for non-turbulent signal with turbulent interferer (Sig, Turb,XT). FIG.10 shows (a) the no interferer and single interferer cases, (b) the FSO link length for both OOK and DPPM systems. The interferer demux rejection is $30 \mathrm{~dB}$ and both interferer and signal from the (remote node (RN) at the same distance. In FIG.10 (a) when the FSO link length increase, the attenuation, scattering, losses of beam spreading and scintillation increase, the required optical power increase. The $C_{n}^{2}$ increased due to the increased of the FSO link length and inevitably the required power increases, if the power transmitted be value high as $0 \mathrm{dbm}$, it can overcome of the problem turbulence. The result of FIG.10 (a) covered all cases turbulent form weak to moderate and strong, In case $\mathrm{C}_{\mathrm{n}}^{2}=1 \times 10^{-13} \mathrm{~m}^{-2 / 3}$ strong turbulence so the required power increase for $\mathrm{C}_{\mathrm{n}}^{2}=1 \times 10^{-13} \mathrm{~m}^{-2 / 3}$ $1_{\mathrm{fso}}=1300$ meter cannot overcome of turbulence. In FIG.10 (b) the required optical power for DPPM system is lower than OOK, so the power penalty of DPPM in a weak turbulence (WT) is 0.2 lower than DPPM. FIG.11 (a) shows the required optical power transmitted $(\mathrm{dBm})\left(\mathrm{BER}\right.$ of $\left.10^{-6}\right)$ as function of the fso link length for single interferer and no interferer with , $\mathrm{L}_{\mathrm{demux}, \mathrm{XT}}=15 \mathrm{~dB}$. For first case the interferer and signal transmitted power in same time, for second case that the interferer and signal transmitted with high $C_{X T}$ obviate effects trublence accentuated crosstalk , $\mathrm{L}_{\mathrm{demux}, \mathrm{XT}}=15 \mathrm{~dB}$ is lower demux or indigent demux. AS in FIG.11 (b) shows the required optical power transmitted (dBm) (BER of $10^{-6}$ ) as function of the fso link length for single interferer and no interferer, $L_{\text {demux, } X T}=15 \mathrm{~dB}$. certainly with increase $C_{n}^{2}$ and transmit beam divergence the required optical power increased. The transmit beam divergence $\grave{e}_{X T}$ for $>$ from $1 \mathrm{mrad}$ not tracking. We assumed that the system with $\grave{e}_{X T}<1 \mathrm{mrad}$ to allow with pointing and tracking about $(0.12 \mathrm{mrad})$. It can be provides the information about the location the receiver. Tracking system also pointing jitter errors [29].

\subsection{SIMULATION RESULTS}

This part shows the simulation result for analyzing DWDM PON/FSO over the noises and atmospheric turbulence accentuated interchannel crosstalk. DWDM free space optics using NRZ line codes is shown in Fig.1. This system is designed using optisystem version 7. These channels are then multiplexed using ideal multiplexer.

TABLE 6: DATA PARAMETER

\begin{tabular}{|c||c||c|}
\hline \multirow{2}{*}{ PARAMETER } & DESCRIPTION & VALUE \\
\hline \hline $\mathrm{n}$ & No. of Channel & 8,32 \\
\hline \hline$\lambda$ & Laser Wavelength & $190 \mathrm{THz}$ \\
\hline \hline $\mathrm{Rb}$ & Data Rate & $40 \mathrm{~Gb} / \mathrm{ps}$ \\
\hline \hline $\mathrm{P}$ & Power & $20 \mathrm{~dB}$ \\
\hline \hline $\mathrm{NF}$ & Frequency Spacing & $100 \mathrm{GHz}$ \\
\hline \hline$l_{\text {fso }}$ & Amplifier Noise Figure & $4.77 \mathrm{~dB}$ \\
\hline \hline$l_{f}$ & FSO Length & $1 \mathrm{~km}$ \\
\hline \hline $\mathrm{DTX}$ & Feeder Fiber Length & $20 \mathrm{~km}$ \\
\hline \hline $\mathrm{DRX}$ & Transmitter Aperture Diameter & $5 \mathrm{~cm}$ \\
\hline \hline$l_{\text {fsoAtt }}$ & Receiver Aperture Diameter & $20 \mathrm{~cm}$ \\
\hline \hline $\mathrm{G}$ & $\begin{array}{c}\text { Atmospheric Channel } \\
\text { Attenuation }\end{array}$ & $25 \mathrm{~dB} / \mathrm{km}$ \\
\hline \hline Optical Amplifier Gain & $30 \mathrm{~dB}$ \\
\hline \hline
\end{tabular}

Initial frequency is $190 \mathrm{THz}$ and frequency spacing is $100 \mathrm{GHz}$. Modulation type are NRZ and RZ. The attenuation of the laser power in depends on two main parameters: Attenuation and Geometrical loss.

The link equation is

$p_{\text {Recieved }}=p_{\text {transmitted }} \frac{\mathrm{dr}^{2}}{\left(\mathrm{~d}_{\mathrm{t}}+\theta_{\mathrm{R}}\right)} 10^{-\alpha \frac{\mathrm{R}}{10}}$

$$
\begin{aligned}
& d_{r}: \text { Receiver aperture diameter }(m) \\
& d_{t}: \text { Transmitter aperture diameter }(m) \\
& \theta: \text { Beam divergence }(\mathrm{mrad})
\end{aligned}
$$

DWDM-FSO system with power of $20 \mathrm{~dB}$ and data rate $40 \mathrm{~Gb} / \mathrm{ps}$ are analyzed USING NRZ-RZ lines codes. The frequency spacing between two adjacent wavelengths is $100 \mathrm{GHz}$. Where data rate per channel at $40 \mathrm{~Gb} / \mathrm{ps}$ for upstream and downstream transmission. The 8 channel DWDM transmitter $(40 \times 8) \quad \mathrm{Gb} / \mathrm{ps}$ and $(40 \times 32)$ channel 1.28 Tera bit, provide high bandwidth for each user and support multiple channel. We analyzed the performance of hybrid DWDM-FSO. We demonstrated high speed DWDMPON/FSO network. And presented the result of Quality factor and BER of 8 and 32 channel of $1 \mathrm{~km}$ fso link as shown in TABLE 7. 
를 Dbl Cick On Objects to open properties. Move Objects with Mouse Drag

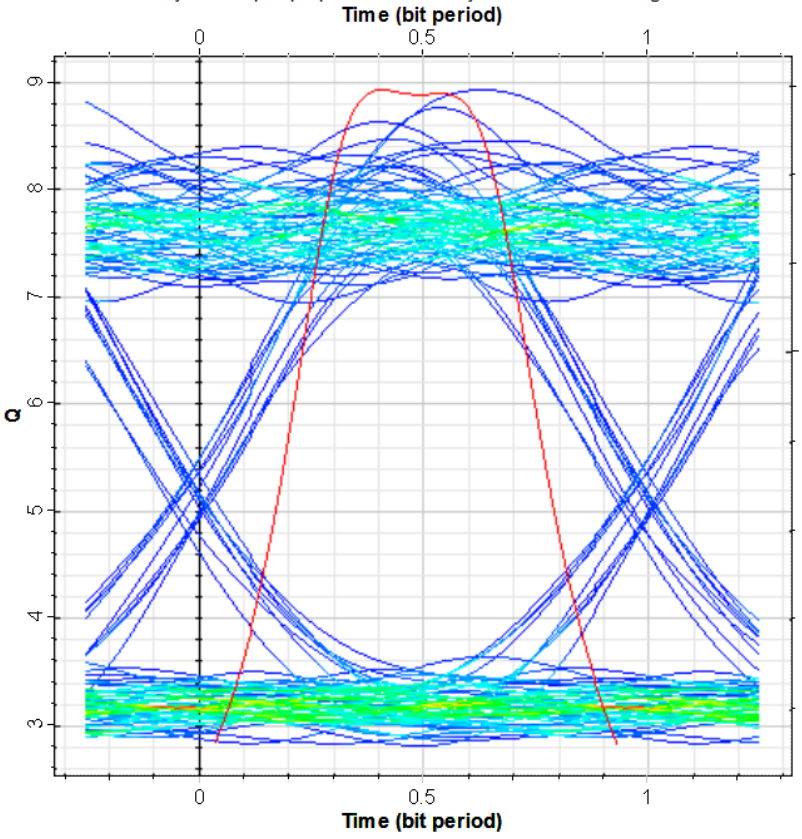

(a)
园

BER Analyzer

Dbl Cick On Objects to open properties. Move Objects w ith Mouse Drag

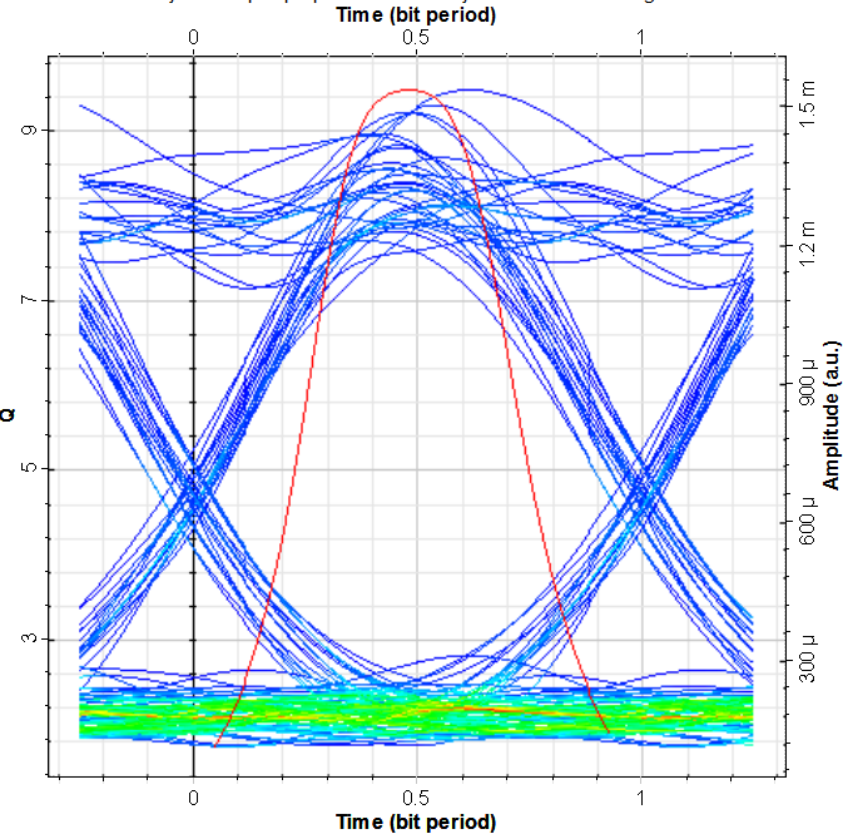

(b)

Figure.12 Simulation Eye diagram for 8channel of DWDM-PON/ FSO link using (a) NRZ line codes. (b) RZ line codes

룰

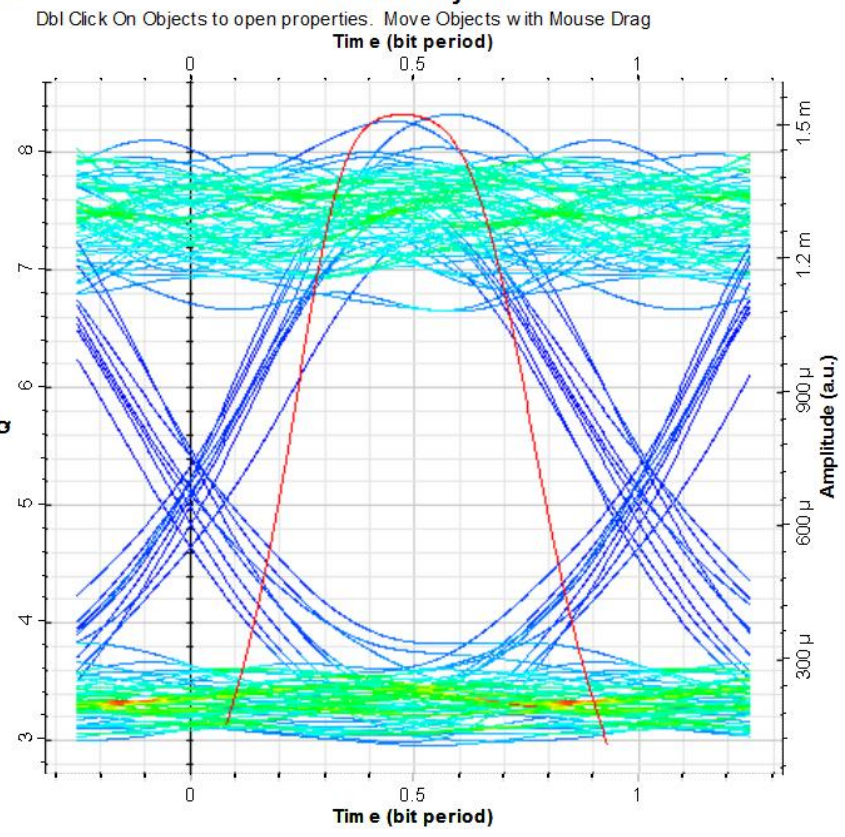

(a)
룹

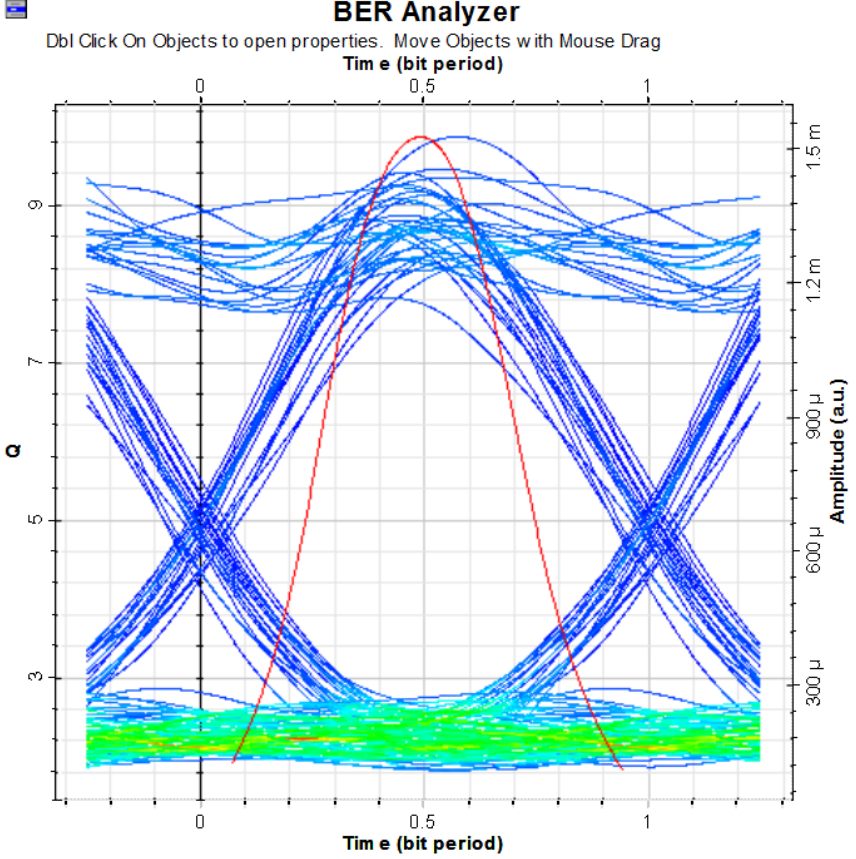

(b)

Figure.13 Simulation Eye diagram for 32 channel of DWDM -PON FSO link using (a) NRZ line codes. (b) RZ line codes

TABLE. 7 PERFORMANCE ANLAYSIS OF 8 AND 32 CHANNEL OD DWDM- PON/FSO

\begin{tabular}{|l||l||l|}
\hline \multicolumn{3}{|c|}{ 8 CHANNEL } \\
\hline \hline MODULATION & QUALITY & BER \\
TECHNIQUES & FACTOR & \\
\hline \hline RZ & 9.48146 & $8.13229 \mathrm{e}-022$ \\
\hline \hline NRZ & 8.93394 & $1.97909 \mathrm{e}-019$ \\
\hline \hline & 32 CHANNEL \\
\hline \hline RZ & 9.86577 & $2.07479 \mathrm{e}-023$ \\
\hline \hline NRZ & 8.32439 & $4.17592 \mathrm{e}-017$ \\
\hline
\end{tabular}




\section{MITIGATION TEWCHNIQUES FOR ATMOSPHERIC TURBULENCE ANALYSIS}

\subsection{MIMO WITH MODULATION ANALAYSIS}

\section{A. MIMO CHANNEL MODEL CAPACITY}

In the previous section we design DWDM-PON /FSO and increased data rates and analysis crosstalk and the effects turbulence and design of laser transceiver with audio transmission and alignment to solve the problem of the beam losses and transmitter divergence angle and in order to mitigate the atmospheric turbulence, scintillation and changing the temperature due to refractive index structure and the pressure of the atmospheric region use with creating a Multiple-Input MultipleOutput (MIMO) is used to achieved transmitting lasers and multiple input multiple output channel. With using the analysis of FSO communication with OOK and DPPM modulation and to illustrate MIMO it is a wireless technology that uses multiple transmitters and receivers to transfer more data at the same time. Multi-user MIMO offers big advantages over conventional pointto-point MIMO: it works with cheap single-antenna. The channel capacity of a multiple antenna with NT transmit and NR receive antennas can be increased factor of $\min (\mathrm{NT}, \mathrm{NR})$ as seen in FIG.16 (b). MIMO FSO transmissions using PPM [17, 30] and Qary PPM [18] have been used both in Rayleigh and lognormal fading regimes. MIMO introduce to free space optical FSO high speed data transmission or high reliability which is a key solution of the imperfections of FSO which is impaired the signal s cause the the main drawbacks such a reflection, scattering, diffraction and refractive index changes in air along the path of light beam. Multiple antenna techniques can be broadly classified into two categories: diversity techniques and spatial-multiplexing techniques [30]. The diversity techniques intend to receive the same information-carrying signals in multiple antennas or to transmit them from multiple antennas as shown in FIG.16 (b) , thereby higher reliability of the transmission. Spatial diversity is used to separate multiple antennas sufficiently to carry out independent wireless channels In time domain, the channel response from $i^{\text {th }} \mathrm{i}^{\wedge}$ th transmit antenna to the $j^{\text {th }} \mathrm{j}^{\wedge}$ th receive antenna can be given as [31].

$\mathrm{h}_{\mathrm{i}, \mathrm{j}}(\mathrm{t})=\sum_{\mathrm{l}=0}^{\mathrm{L}-1} \alpha_{\mathrm{i}, \mathrm{j}}(\mathrm{l}) \delta\left(\mathrm{t}-\tau_{1}\right)$

Where $\alpha_{\mathrm{i}, \mathrm{j}}(l)$ is the multi-path gain coefficient, $\mathrm{L}$ indicates the number of paths resovable of the number of resolvable paths, and $\hat{o}_{1}$ represent the path delay time $i_{1}^{\text {th }}$ of multi-path component.The frequency response of channel is given by [31].

$\mathrm{h}_{\mathrm{i}, \mathrm{j}}^{\mathrm{k}}(\mathrm{f})=\sum_{\mathrm{l}=0}^{\mathrm{L}-1} \alpha_{\mathrm{i}, \mathrm{j}}^{\mathrm{K}}(\mathrm{l}) \mathrm{e}^{-\mathrm{j} 2 \pi \mathrm{f \tau l}}$

Multiple receiver outputs can be combined using selection combining (SC) a profit Equal Gain Combining (EGC) or Maximum Ratio combining (MRC) as shown in FIG.19, 20. Replace one high power transmitter with multiple transmitters of the same total energy may increase for system diversity to improve the performance thus. The received signal at antenna $\mathrm{j}$ where $\mathrm{j}=1$, $2, n_{R}$ at time represented by $r_{t}^{j}$ is given by, [31].

$\left(r_{t}^{j}\right)=\sum_{i=1}^{n_{T}} h_{j, i}^{t} x_{t}^{i}+n_{t}^{j}$

Thus, the received signal vector can be represented as,

$\left(r_{-} t\right)=H_{t} x_{x}+n_{t}$

\section{B. ALAMOUTI BLOCK CODE}

Alamouti code block is the only complex code block contains the data rate of $(I)$ while achieving maximum diversity gains seen FIG.16 (a). This is achieved by using performance space time following code block Alamouti encoded signal is transmitted from two antennas to send over OFDM symbol period [32]. During the first symbol in time at $(t=T)$, two symbol $\left(X_{1}\right)$ and $\left(X_{2}\right)$ transmitted from two antenns. During the second symbol time $(t=$ $2 T)$, symbols are transmitted again, where conjugate of second symbol $\left(X_{2}{ }^{*}\right)$ transmitted from the first antenna and $X_{1} *$ transmitted from the second antenna. We assumed that two channel $X_{1}(t), X_{2}$ $(t)$

$$
\begin{aligned}
& X_{1}(t)=X_{1}(t+T) \equiv X_{1}=\left|X_{1}\right| e^{j \vartheta_{1}} \\
& X_{2}(t)=X_{2}(t+T) \equiv X_{2}=\left|X_{2}\right| e^{j \vartheta_{2}}
\end{aligned}
$$

Where $\left|X_{1}\right|$ and $e^{j \vartheta_{1}}$ denote to the amplitude and phase of Two symbol.

\section{SPACE TIME CODING}

Space-time coding (STC) [33] exploits channel diversity provided by both a time and space at MIMO and increased greatly. The capacity of the system as well as to improve the reliability of the wireless link. STC signals based on designing the code with channel for transmission and receiving diversity.

\section{SPACE TIME TRELLIS CODE}

In 1998, V. Tarokh, H. Jafarkhani, and A. R. proposed the model of STTCs using multiple transmit antennas. STTCs can concurrently provide substantial coding gain, spectral efficiency and diversity improvement. But with the increase in number of antennas and the size of the modulation there is exponential increase in decoding complexity set is a major drawback. Multiple-input multiple-output (MIMO) system with $n_{R}$ receive antennas and $n_{T}$ transmit antennas as shown in FIG.16 (b). We evaluate the effect of receive diversity on the error performance of the code. Performance is calculated by using 2 transmit antennas and different number of receive antennas for Rayleigh fading channel. The performance of a WSTTC system for Rayleigh fading channel is given by plotting Frame Error Rate (FER) against SNR (dB). FER performance for 4QPSK constellation, STTC system for Rayleigh fading channel is shown in below FIG.18. Performance is calculated with 2 transmits antennas i.e., and different number of receive antennas for $n_{r}=$ $1,2,4$.

\begin{tabular}{|c|c|c|}
\hline Parameter & Symbol & Value \\
\hline Wavelength & $\lambda$ & $1550 \mathrm{~nm}$ \\
\hline Receiver radius & A & $6 \mathrm{~cm}$ \\
\hline Link distance & $\mathrm{L}$ & $1550 \mathrm{~m}$ \\
\hline $\begin{array}{l}\text { Refractive index structure } \\
\text { parameter }\end{array}$ & $\mathrm{C}_{\mathrm{n}}{ }^{2}$ & $1.5 \times 10^{-15} \mathrm{~m}^{-2 / 3}$ \\
\hline Beam waist radius & $\mathrm{W}_{\mathrm{o}}$ & $2 \mathrm{~cm}$ \\
\hline Inter Spacing between $\mathrm{Tx}$ & $\mathrm{D}$ & $20 \mathrm{~cm}$ \\
\hline Phase front radius & $\mathrm{F}_{\mathrm{o}}$ & $-10 \mathrm{~cm}$ \\
\hline
\end{tabular}

TABLE .8 PARAMETERS FOR SYSTEM ANALYSIS 


\subsection{SIMULATION RESULT}

The software used for simulation is MATLAB and evaluate the performance MIMO-STBC coded OFDM and Alamouti block code as shown in FIG.17 and 19. FIG.17 shows that the outage probability versus SNR for diversity combining techniques. As the SNR increases, the error in the transmitted data decreases. With achieving the MIMO and diversity system can overcome of the obstruction of FSO which suffer from the interchaneel crosstalk and atmospheric turbulence. The performance is achieved by increasing the number of odes NR in the receiver side, BER and the outage probability are analyzed with Modulation and Diversity Schemes. The simulation parameters used for FSO MIMO system is given in TABLE 8. The bit error rate and outage probabilities are analyzed for different diversity combining techniques for FSOMIMO system, which improves the performance of the system. For indoor usages, small FSO nodes the receiver radius is 1-6 cm and for outdoor usages, the receiver radius is $10-25 \mathrm{~cm}$ is used for larger. In FIG.17 Space Time block code can be used to reduce the BER of a system, without losing of data rate.

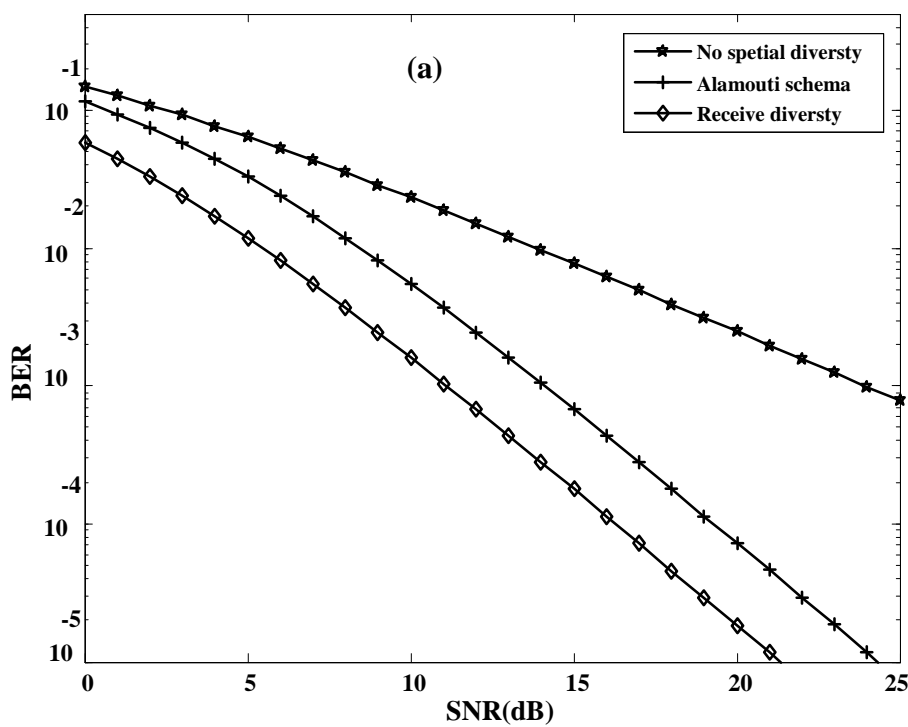

10

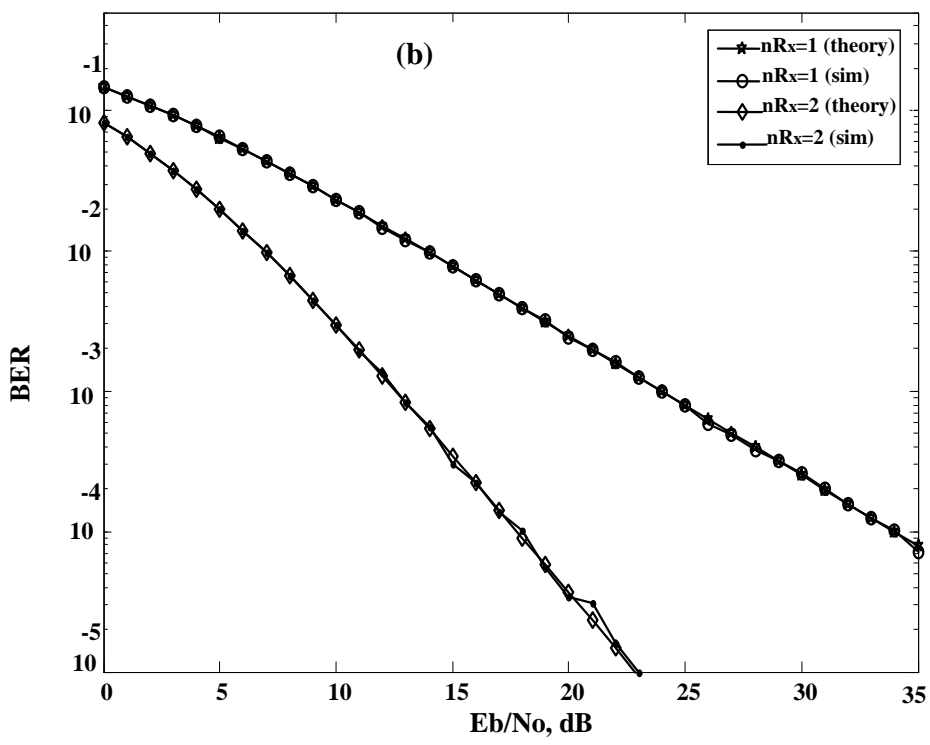

Figure. 16 BER against SNR for (a) curves of different MIMO schemes compared to a SISO implementation.(b) BPSK modulation in a Rayleigh fading channel with selection diversity.

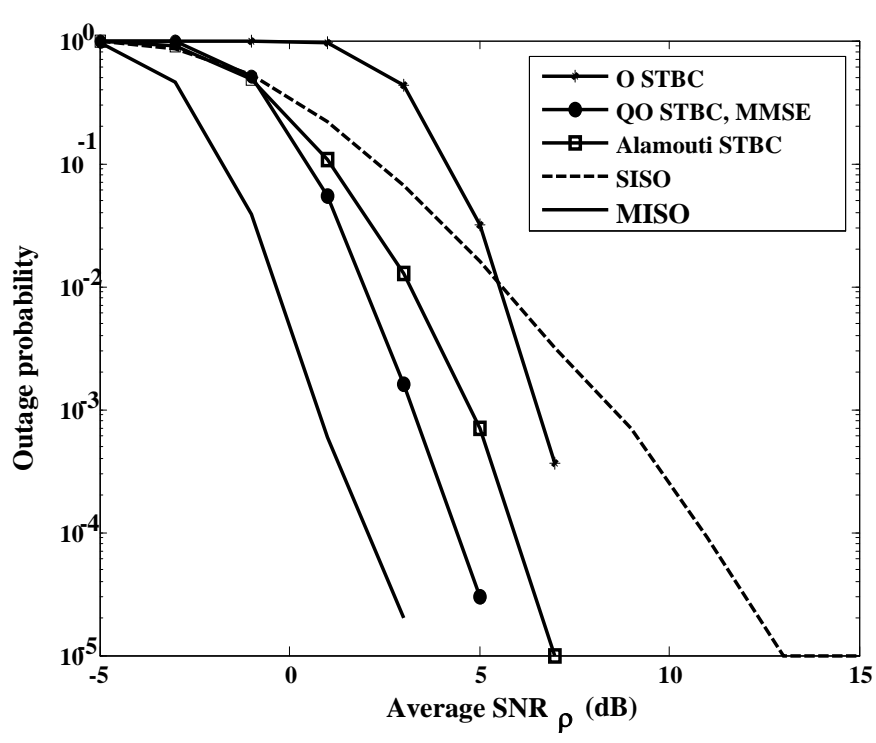

FIGURE. 17 Outage Probabilities Vs. SNR for diversity combining techniques.

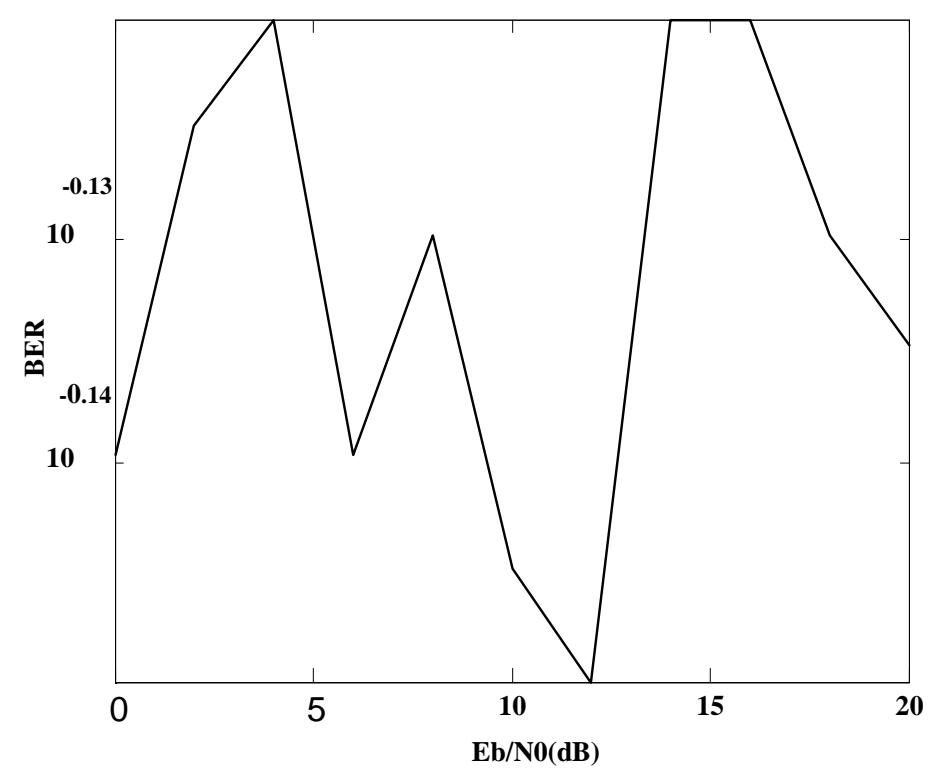

FIGURE. $18 \mathrm{~Eb} / \mathrm{N}_{0}(\mathrm{~dB})$ vs Bit error rate.

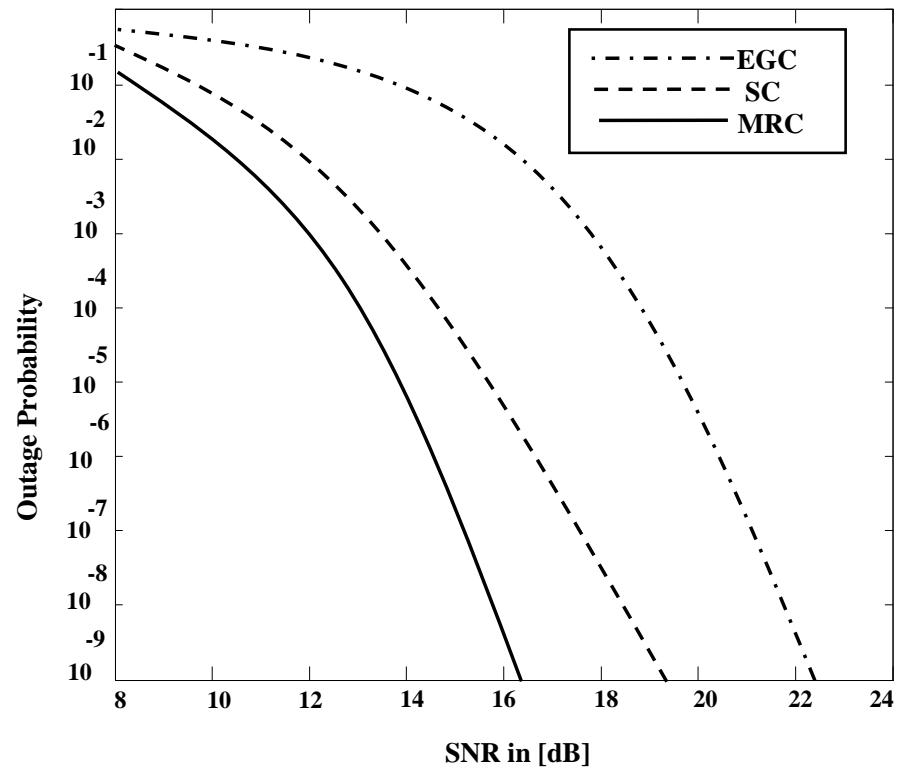

FIGURE. 19. Outage Probability Vs SNR for diversity combining techniques for Equal Gain Combining (EGC) and Maximum Ratio combining (MRC). 


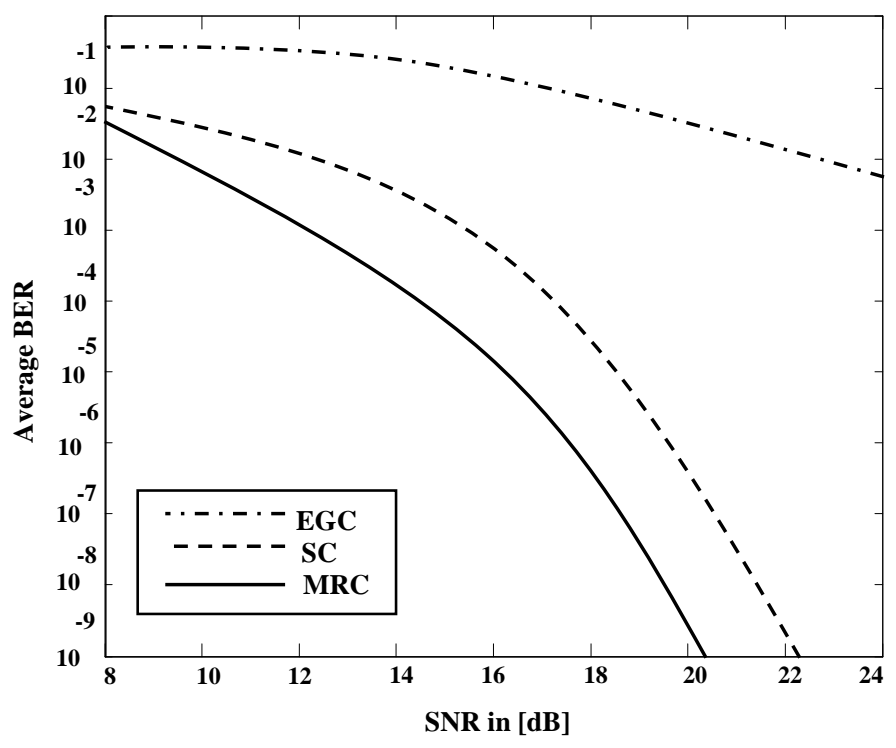

FIGURE. 20. Average BER Vs SNR for diversity combining techniques for Selection Combining Equal Gain Combining (EGC) and Maximum Ratio combining (MRC).

\subsection{PROTCOL FUNCTION AND CODING}

The function of coding techniques on a higher level of the communications system. Correct the errors in data processing and electrical contacts.

- Forward error correction: In forward error correction (FEC) Transmitted redundant bits in the data stream, this corrects errors in the incoming received data stream. Always limited the ability to correct errors by repetition and added the type of code .Transmitted redundant bits in the data stream can increases reliability of data transmission [36].

- Protocol functions: At the protocol level there are a variety of techniques to ensure the authenticity of the transmitted data. The basic principle that the return channels is used to refer to the loss of data. This signal causes the transmitter to send the missing parts of the data stream.

\subsection{TECHNIQUES OF ERROR CORRECTIONS}

- $\quad$ Proactive Error Correction (FEC): The use of error correction layer codes was investigated by simulation and presented the result in [37]. Fading affect long sequences of bits necessary to use very long code words as shown FIG.21.

- Reactive Error Correction (ARQ): Sending and receiving data by techniques of automatic repeat request (ARQ) protocols. In general there are four types of (ARQ) protocols, Stop-and-Wait, Go-back-N, Selective-Repeat and hybrid ARQ-FEC protocols.

\subsection{ENCODING AND DECODING SECURITY FOR FSO}

FSO modulated of the light beam in free space to transmit data which data is transmitted by propagation of light in free space allowing connectivity.

\section{A. HADAMARD CODE GENWERATOR}

The Hadamard code is used for error detection and error correction to correct error of the transmitting message with set of orthogonal codes. It is based on Hadamard matrices of individual rows [38]. Hadamard matrices of $1^{\prime} S$ and $-1^{\prime} S$ where columns are orthogonal $\mathrm{H}^{\prime} * \mathrm{H}=\mathrm{n}^{*} \mathrm{I},\left[\begin{array}{ll}\mathrm{n} & \mathrm{n}\end{array}\right]=\mathrm{size}(\mathrm{H})$ and $\mathrm{I}=$ eye $(n, n)$.

\subsection{FADING CHANNEL MODELING}

To determine the reliability of free space optics, we use model for the turbulence and designing higher performance for link margin .The link budget equation $n$ model is given by [39].

$$
P_{\text {received }}=P_{\text {transmit }} \frac{A_{\text {receiver }}}{(\theta L)^{2}} e^{-\alpha L}
$$

Where $P_{\text {recieved }}$ and $P_{\text {transmit }}$ are power at receiver and transmitter respectively (watt). $A_{R X}$ is aperture area of the receiver $\left(m^{2}\right), \theta$ is beam divergence angle $(\mathrm{mrad}), \mathrm{L}$ is distance between transmitter and receiver $(\mathrm{m}), \alpha$ is atmospheric attenuation $(\mathrm{dB} / \mathrm{km})$.

\section{A. RAYLEIGH DISTRIBUTION}

The Rayleigh model is used the gain of the channel. The scintillation index of fading is 1 . The channel fading AMPLITIDE "a" for Rayleigh distribution or PDF gain is written in [15, 40]

$$
f_{A}(\mathrm{a})=2 \mathrm{ae}^{-\mathrm{a}^{2}}
$$

\section{B. LOG-NORMAL DISTRIBUTION}

The Lognormal model is used in cases less fading (weak turbulence) [38].

$$
f_{A}(a)=\frac{1}{\sqrt{2 \pi \sigma a^{\exp }}}\left(-\frac{\left(\operatorname{In} a-\mu^{2}\right)}{2 \sigma^{2}}\right)
$$

Where the parameters $\mu$ and $\sigma^{2}$ denote mean and variance respectively. The relation $\mu=-o^{2}$ mean path intensity $E\left[A^{2}\right]=1$. The scintillation index (S.I) ranges between 0.4 and 1 .

FIG.22 shows the probability density function (PDF) of both Rayleigh and log-normal fading. Two values for scintillation index (S.I) for the log-normal would be clear for a higher density in the Rayleigh with low values of 'a' better than of the log-normal case and it is fading on the performance of the system. 


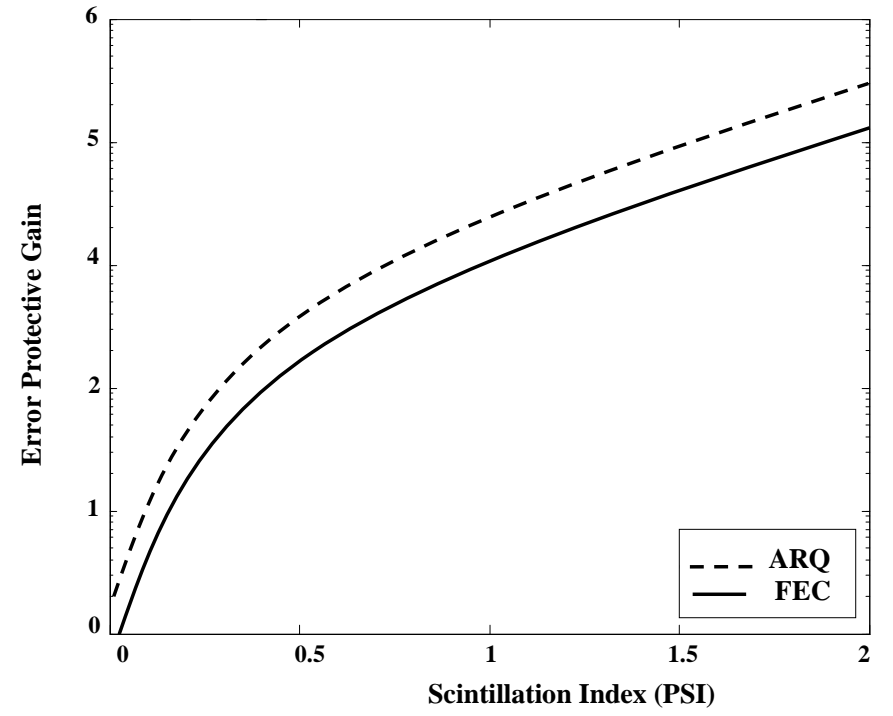

Figure. 21 Error protection gain over the power scintillation index (PSI).

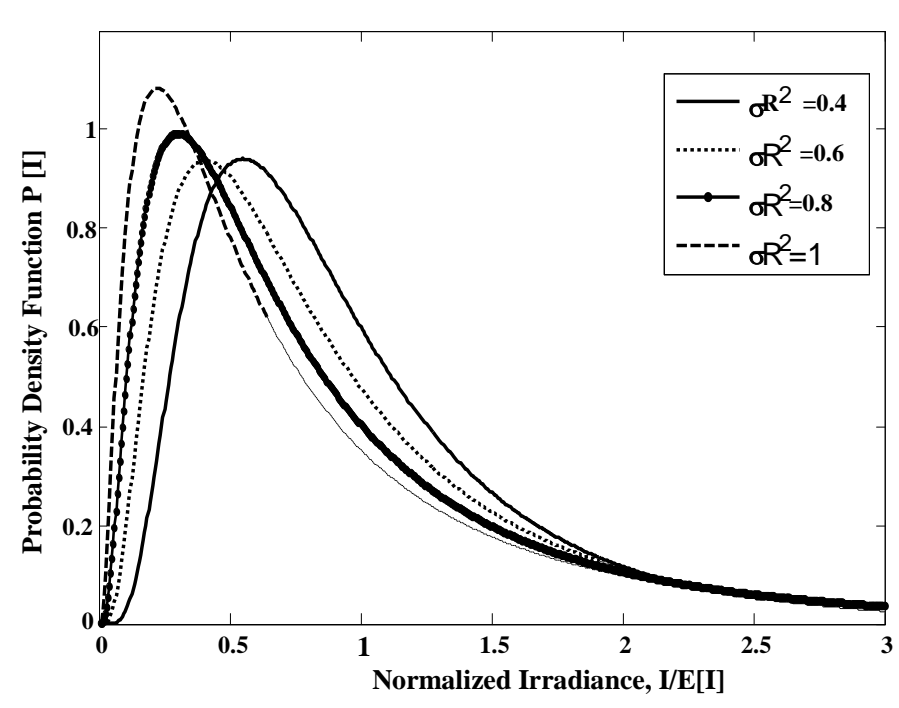

Figure. 22 Log-normal and Rayleigh pdfs.

\section{REFERENCES}

\section{CONCLUSION}

We design a system model of WDM-PON/FSO which can provide with higher bandwidth and growing demand of traffic and analyzed WDM-FSO channel which accentuated interchannel crosstalk, interference and noises. We calculate the total OLT receiver noise variance is the summation of the signal shot noise; ASE shot noise, beat noise, and ASE-ASE noises variances are is main problem of system degradation. With calculation of matlab obtained values of error floor found in turbulence atmospheric with modulation format such as DPPM, On-Off key and adaptive threshold. DPPM systems require lower optical power compared to OOK systems, but suffers a small loss in sensitivity as the turbulence strength increases. Forward error correction (FEC) would benefit greatly the system in dealing with error floors and improving the achievable target BER To overcome of the losses of beam spreading and pointing error due to Transmitter divergence angle, We design a alignment method for laser transceiver with audio transmission over free space optics in order to achieve an integrated and united and have a successful system of robust is not affected with turbulence of the channel. The results obtained indicate that in a clear atmosphere with a sufficiently high signal to-crosstalk ratio. To overcome of the problem of effects of crosstalk and fading been using MIMO and diversity techniques in order to achieve an integrated and united and have a successful system of robust is not affected with turbulence of the channel. The results obtained indicate that in a clear atmosphere with a sufficiently high signal to-crosstalk ratio. We showed that RS coding alone is not robust against (even weak) channel turbulence. The simulation result illustrate that out of Alamouti and STBC, STBC are worth to be implemented on the wireless communication systems. As they are providing far less bit error rate as compare to no coding communication. Increase in the number of transmit and receive antennas enhances the performance of STBC.
[1] V. W. S. Chan, "Free-space optical communications," IEEE/OSAJ. Lightw. Technol., vol. 24, no. 12, pp. 4750 4762, Dec. 2006.

[2] J. H. Shapiro and R. C. Harney, "Burst-mode atmospheric optical communication," in Proc. Nat. Telecommun. Conf., 1980, pp. 27.5.1_27.5.7.

[3] E. Ciaramella, Y. Arimoto, G. Contestabile, M. Presi, A. D’Errico,V. Guarino, and M. Matsumoto, "1.28 terabit/s (32x40 Gbit/s)WDM transmission system for free space optical communications," IEEE J. Sel. Areas. Commun., vol.27, no.9, pp.1639-1645, Dec. 2009.

[4] S. Karp, R. M. Gagliardi, S. E. Moran, and L. B. Stotts, Optical Channels: Fibers, Clouds, Water and the Atmosphere. New York: Plenum, 1988.

[5] R. Ramaswami and K. N. Sivarajan, Optical NetworksA Pratical Perspective, 2nd ed. London: Academic, 2002.

[6] H. Manor and S. Arnon, "Performance of an Optical Wireless Communication System as a Function of Wavelength," Applied Optics, vol. 42, no. 21, pp. 4285 4294, July 2003.

[7] S. Arnon, "Optical Wireless Communications," Encyclopedia of Optical Engineering, pp. 1866 1886, 2003].

[8] Ansari, N., Zhang, J.: 'Media access control and resource allocation for next generation passive optical networks' (Springer, 2013).

[9] Zuo, T.J., Phillips, A.J.: 'Performance of burst mode receivers for optical digital pulse position modulation in passive optical network application', IET Optoelectron., 2009, 3, (3), pp. 123-130.

[10] A. O. Aladeloba, M. S. Woolfson, and A. J. Phillips, "WDM FSO network with turbulence-accentuated interchannel crosstalk," Opt. Commun. Netw., vol. 5, no. 6, pp. 641-651, June 2013.

[11] D. Killinger, "Free space optics for laser communication through the air," Opt. Photon. News, vol. 13, no. 10, pp. 36-42, Oct. 2002.

[12] I. T. Monroy and E. Tangdiongga, Crosstalk in WDM Communication Networks. Norwell, MA: Kluwer Academic, 2002.

[13] Aladeloba, A.O., Phillips, A.J., Woolfson, M.S.: 'Performance evaluation of optically preamplified digital pulse position modulation turbulent free-space optical 
communication systems', IET Optoelectron., 2012, 6, (1), pp. 66-74.

[14] Aldibbiat, N.M., Ghassemlooy, Z., McLaughlin, R.: 'Indoor optical wireless systems employing dual header pulse interval modulation (DH-PIM)', Int. J. Commun. Syst., 2005, 18, (3), pp. 285-305.

[15] Ghassemlooy, Z., Popoola,W., Rajbhandari, S.: 'Optical wireless communications -system and channel modelling with MATLAB' (CRC Press, London, 2013, 1st edn.).

[16] X. Zhu and J. M. Kahn, "Free-space optical communication through atmospheric turbulence channels," IEEE Trans. Commun., vol. 50, pp. 12931300, Aug. 2002.

[17] S. G. Wilson, M. Brandt-Pearce, Q. Cao, and J. H. Leveque, "Free-space optical MIMO transmission with $Q$-ary PPM," IEEE Trans. Commun., vol. 53, pp. 14021412, Aug. 2005.

[18] S. G. Wilson, M. Brandt-Pearce, Q. Cao, and M. Baedke, "Optical repetition MIMO transmission with multipulse PPM," IEEE J. Sel. Areas Commun., vol. 23, pp. 19011910, Sept. 2005.

[19] M.Abtahi, P. Lemieux, W. Mathlouthi, and L. A.Rusch,"Suppression of turbulence-induced scintillation in free-space optical communication systems using saturated optical amplifiers,"J. Lightwave Technol., vol. 24, pp. 4966-4973, 2006.

[20] Phillips, A.J., Cryan, R.A., Senior, J.M.: 'An optically preamplified intersatellite PPM receiver employing maximum likelihood detection', IEEE Photonic Technol. Lett., 1996, 8, (5), pp. 691-693.

[21] L. C. Andrews, R. L. Phillips, and C. Y. Hopen, Laser Beam Scintillation with Applications. Bellingham, Washington: SPIE Press, 2001.

[22] Andrews, L.C., Phillips, R.L.: 'Laser beam propagation through random media' (SPIE Press, Bellingham, Washington, 2005, 2nd edn.).

[23] Majumdar, A.K.: 'Free-space laser communication performance in the atmospheric channel', J. Opt. Fiber Commun. Rep., 2005, 2, pp. 345-396.

[24] Khalighi, M., Schwartz, N., Aitamer, N.,Bourennane, S.: 'Fading reduction by aperture averaging and spatial diversity in optical wireless systems', J. Opt. Commun. Netw., 2009, 1, (6), pp. 580-593.

[25] Y. Dikmelik and F. M. Davidson, "Fiber-coupling efficiency for free-space optical communication through atmospheric turbulence," Appl. Opt., vol. 44, pp. 49464952, Aug. 2005.

[26] M. A. Al-Habash, L. C. Andrews, and R. L. Phillips, "Mathematical model for the irradiance probability density function of a laser beam propagating through turbulent media," Opt.Eng., vol. 40, pp. 1554-1562, Aug. 2001.

[27] J. Li, J. Q. Liu, and D. P. Taylor, “optical communication using subcarrier PSK intensity modulation through atmospheric turbulence channels," IEEE Trans.Commun., vol. 55, no. 8, pp. 1598_1606, Aug. 2007.

[28] A. Jurado-Navas, J. M. Garrido-Balsells, M. CastilloVazquez, and A. Puerta-Notario, "Closed-form expressions for the lower-bound performance of variable weight multiple pulse-position modulation optical links through turbulent atmospheric channels," IET Commun., vol. 6, no. 4,pp. 390-397, Mar. 2012.

[29] A. O. Aladeloba, A. J. Phillips, and M. S. Woolfson, "DPPM FSO communication systems impaired by turbulence, pointing error and ASE noise," in 14th Int. Conf. on Transparent Optical Networks (ICTON), Coventry, UK, 2012.

[30] Golden, G.D., Foschini, C.J., Valenzuela, R.A., and Wolniansky, P.W. (1999) Detection algorithm and initial laboratory result using V-BLAST space-time communication architecture. Electron. Lett., 35(1), 14-15.

[31] Performance Analysis of MIMO-OFDM for 4G Wireless Systems under Rayleigh Fading Channel, Md. Mejbaul
Haque, Mohammad Shaifur Rahman and Ki-Doo Kim, International Journal of Multimedia and Ubiquitous Engineering Vol. 8, No. 1, January 2013.

[32] 39- S.M. Alamouti, A simple transmit diversity technique for wireless communicationsIEEE Journal o Selected Areas on Communication, vol. 16, no. 8,(1998)October, pp. 1451-1458.

[33] H. Jafarkhani, Space-time coding: theory and practice, Cambridge university press, 2005.

[34] Channel coding and time-diversity for optical wireless links, FangXu, Ali Khalighi *,Patrice Caussee',Salah Bourennane, (02008 Optical Society of America OCIS codes: 060.2605 Free space optical communication, 060. 4510 Optical communications.

[35] G. Fettweis and H. Meyr," High-Speed Parallel Viterbi Decoding: Algorithm and VLSI-Architecture," IEEE Communications Magazine, vol.29,pp.46-55,May1991.

[36] Mitigation Techniques for Atmospheric Turbulence Effects: M. Knapek ${ }^{1}$, B. Epple ${ }^{2}$, German Aerospace Center, Germany16.1, 16.3 , German Aerospace Center, Germany 16.2 , National University of Ireland, Ireland 16.3 .

[37] H. Henniger, F. David, D. Giggenbach, and C. Rapp: "Evaluation of FEC for the atmospheric optical IM/DD channel." Proc. SPIE, Vol. 4975, p. 1-11, Free-Space Laser Communication Technologies XV, 2003.

[38] Rakhi.J.Nair, S.Manikkandan: Protection of WDM FSO Network Over FADING Channel: International Journal of Innovative Research in Science, Engineering and technology, Vol.3, Issue 4, April 2017.

[39] Heinz Willebrand, and Baksheesh S. Ghuman, " Fiber Optics without Fiber," IEEE, 2001.

[40] Scott Bloom, "Physics of free space optics," 2002. 